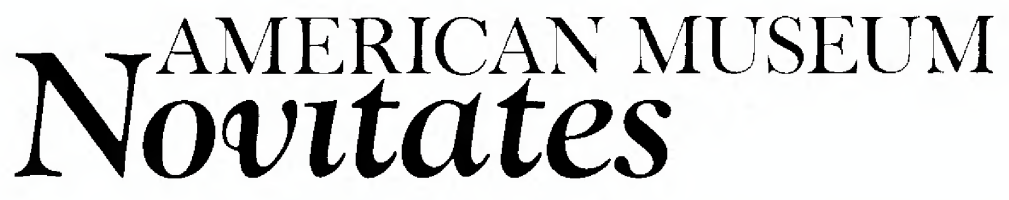

PUBLISHED BY THE AMERICAN MUSEUM OF NATURAL HISTORY
CENTRAL PARK WEST AT 79TH STREET, NEW YORK, NY 10024
Number 3318, 37 pp., 24 figures, 2 tables

\title{
Phylogeny of Eulithis Hübner and Related Genera (Lepidoptera: Geometridae), with an Implication of Wing Pattern Evolution
}

\author{
SEI-WOONG $\mathrm{CHOI}^{1}$
}

\begin{abstract}
This study investigates a mimicry ring in East Asia, comprising the ennomine genus Abraxas Leach and several larentiine genera, including Eulithis Hübner, Chartographa Gumppenberg, Callabraxas Butler, Calleulype Warren, Gandaritis Moore, and Eucosmabraxas Prout. A cladistic analysis of these latter genera was undertaken using six outgroups and 51 morphological characters. The preferred cladogram, derived after the successive weighting, recognized seven monophyletic groups: Antepirrhoe Warren rev. gen., Evecliptopera Inoue, Gandaritis, Callabraxas, Lobogonodes Bastelberger, Eustroma Hübner and Eulithis, and resulted in three new synonyms: Chartographa, a synonym of Callabraxas, and Eucosmabraxas and Calleulype, synonyms of Gandaritis. Three revived combinations are proposed: Antepirrhoe atrifasciata (Hulst), A. semiatrata (Hulst), and A. fasciata (Barnes and McDunnough). Nine new combinations are also proposed: Gandaritis powellata (Ferguson and Choi), G. pyraliata (Denis and Schiffermüller), G. atricolorata (Grote and Robinson), G. placida (Butler), G. whitelyi (Butler), G. evanescens (Butler), Callabraxas fabiolaria (Oberthür), C. plurilineata (Walker), and C. compositata (Guenée). Wing patterns and a distinctive abdomen have undergone convergent evolution, evolving at least twice within Eulithis and related genera: once in the genus Gandaritis, and again in Callabraxas. A key to the genera is provided as well as diagnoses, species lists, biology, and distributions for each.
\end{abstract}

\footnotetext{
${ }^{1}$ Kalbfleisch Research Fellow, Division of Invertebrate Zoology, American Museum of Natural History. Present address: Dr. Sei-Woong Choi, Department of Environmental Education, College of Engineering, Mokpo National University, 61 Dorim-ri, Chungkye-myon, Muan-gun, Chunnam 534-729, South Korea. e-mail: choisw@apollo.mokpo.ac.kr.
} 


\section{INTRODUCTION}

Lepidopteran insects attract people with their diverse wing patterns and bright color. The conspicuous characteristics of these insects are viewed as a result of natural selection (Fisher, 1930). Mimicry complexes of tropical butterflies and day-flying moths are common and are fairly well investigated (e.g., Sheppard, et al., 1985; Brown, 1988; Beccaloni, 1997; Vane-Wright et al., 1999). Recent studies of these mimicry patterns based on robust phylogenetic hypotheses revealed a highly complex evolutionary history (e.g., Brower, 1996; Miller, 1996).

While mimicry patterns of geometrid adults and larvae are described, the mimetic behavior of these geometrids or their evolutionary patterns have barely been investigated. Dietze (1871) listed two examples of geometrid mimicry. The first is a white wing, diurnal geometrid, Siona lineata (Scopoli). This is similar to the cabbage butterfly (Pieris napi) in wing patterns, especially on the underside of the hindwing. The second is the pair of Epirranthis diversata (Denis and Schiffermüller) and Archiearis parthenias (Linnaeus). Poole $(1969,1970)$ described the mimetic behaviors of geometrid larvae that resemble parts of their foodplant, or morphological resemblance between two different geometrids that feed on the same host plant. Beccaloni (1997) listed two ennomine genera, Emplocia pallor Druce and Nephodia panthea panthea Druce, being a mimicry complex of Neotropical ithomiine butterflies.

In East Asia, mimetic larentiine moths belong to a well-recognized mimicry complex. Prout (1914), in his comprehensive work on Palearctic Geometridae, noted that several larentiine moth genera, together with Eulith$i s$, mimic the ennomine genus Abraxas Leach. The mimicry complex comprises four larentiine groups: species of Callabraxas Butler and Gandaritis Moore, Eulithis convergenata, and Xanthorhoe abraxina (Butler) (fig. 1). This mimicry complex also includes several ennomine genera that resemble the genus Abraxas and occur sympatrically in the Indo-Australian region (e.g., Bracca Hübner, Craspedosis Butler, Pogonopygia Warren, and Dilophodes Warren). The mimicry pattern is summarized as follows: fore- wing white, with dotted central fascia and subterminal lines; a large, yellowish dorsal marking $4 / 5$ the distance to the tornus; hindwing with same central and subterminal lines as forewing; yellow abdomen with black dots.

The genus Abraxas comprises 170 species from the Palearctic and Indo-Australian regions, having the highest species diversity in East Asia; about $80 \%$ of the described species are known from central China to Japan, including Taiwan. The genus Eulithis Hübner comprises about 23 species from the Holarctic region, while its close relatives such as Callabraxas, Calleulype Warren, Gandaritis, Chartographa Gumppenberg, and Eucosmabraxas Prout exclusively occur in East Asia. This sympatric distribution of Abraxas and several larentiine genera implies a mimicry complex.

Adults of Abraxas are easily recognized by their white wings, blackish medial bands and yellowish markings on the termen of forewing. They rest on the upperside of leaves during the day. Prout (1915) noted that the species are excessively abundant and they are little persecuted by birds and other predators despite their conspicuousness. Larvae of this species are semi-gregarious and are conspicuous, being white with black dots and reddish marks (Ford, 1955; Carter and Hargreaves, 1986). A. grossulariata (Linnaeus), the type species of Abraxas, feeds on Ribes, Crataegus monogyna, Euonymus japonicus, Sedum telephium, Prunus spinosa, and Calluna vulgaris in Europe (Ford, 1955; Carter and Hargreaves, 1986). In Japan, a wide range of hostplants of Abraxas is recorded, including Caprifoliaceae, Celastraceae, Ericaceae, Fagaceae, Oleaceae, Pinaceae, and Salicaceae (Sato and Nakajima, 1975; Holloway, 1993). Unlike Abraxas, the biologies of Eulithis and other larentiine genera are poorly known.

In the present study, my primary aim is to test the monophyly of the larentiine genera that mimic Abraxas and to infer the phylogenetic relationships among them, based on morphological characters. All members involved in this mimicry complex are placed in the tribe Cidariini, except Xanthorhoe that belongs to the sister tribe Xanthorhoini. Monophyly of the Cidariini has been estab- 


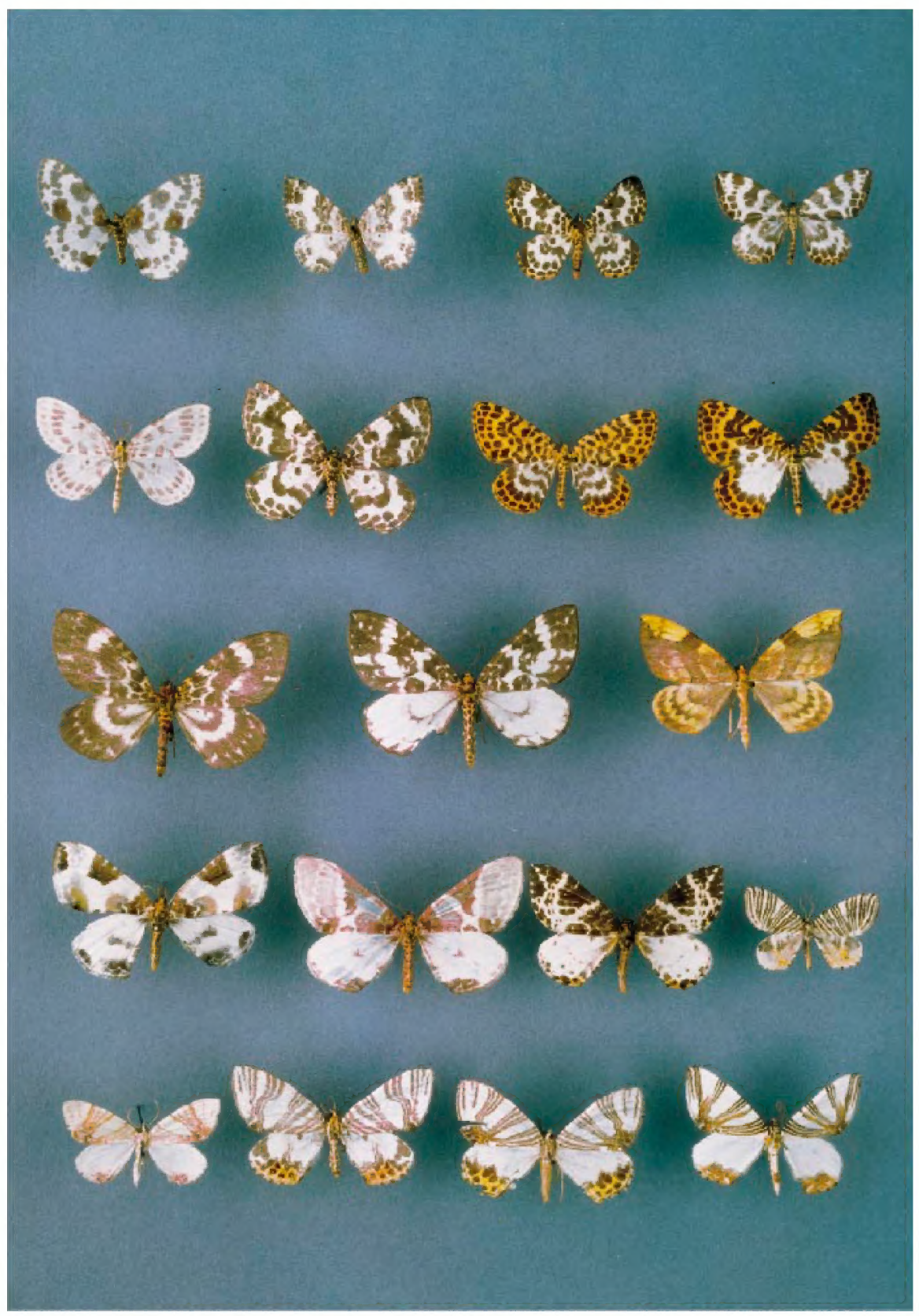

Fig. 1. Adults of Abraxas Leach and its larentiine mimics. 1st row (from left to right). Abraxas sylvata (Ennominae); Xanthorhoe abraxina; Eucosmabraxas (= Gandaritis) placida; Calleulype (= Gandaritis) whitelyi. 2nd row. Callabraxas (= Gandaritis) maculata; Eucosmabraxas (= Gandaritis) evanescens; E. (= Gandaritis) pseudolargetaui; E. (= Gandaritis) octoscripta. 3rd row. Gandaritis agnes; G. subalba; G. fixseni. 4th row. Chartographa (= Callabraxas) fabiolaria; C. (= Callabraxas) trigoniplaga; $C$. (= Callabraxas) intersectaria; $C$. (= Callabraxas) plurilineata. 5th row. Eulithis convergenata; Chartographa $(=$ Callabraxas $)$ compositata; C. $(=$ Callabraxas $)$ ludovicaria; C. $(=$ Callabraxas) convexa (Larentiinae). 
TABLE 1

Classifications of Eulithis and Other Asian Genera

\begin{tabular}{|c|c|c|c|c|}
\hline $\begin{array}{c}\text { Prout }^{a} \\
(1914,1937-38)\end{array}$ & $\begin{array}{l}\text { Inoue } \\
(1992)\end{array}$ & $\begin{array}{l}\text { Viidalepp } \\
\text { (1996) }\end{array}$ & $\begin{array}{l}\text { Xue and Zhu } \\
\text { (1999) }\end{array}$ & $\begin{array}{c}\text { Choi } \\
\text { (this study) }\end{array}$ \\
\hline $\begin{array}{l}\text { Lobogonodes } \\
\quad \text { (subg. Lobogonodes) } \\
\text { (subg. Microlygris) }\end{array}$ & $\begin{array}{l}\text { Lobogonodes } \\
\text { Microlygris }\end{array}$ & Lobogonodes & $\begin{array}{l}\text { Lobogonodes } \\
\text { Microlygris }\end{array}$ & Lobogonodes \\
\hline $\begin{array}{l}\text { Eustroma } \\
\text { Callabraxas }\end{array}$ & Eustroma & Eustroma & Eustroma & $\begin{array}{l}\text { Eustroma } \\
\text { Callabraxas }\end{array}$ \\
\hline $\begin{array}{l}\text { Calleulype } \\
\text { (subg. Calleulype) } \\
\text { (subg. Callygris) }\end{array}$ & Callygris & Calleulype & Calleulype & \\
\hline $\begin{array}{l}\text { Lygris } \\
\quad \text { (subg. Chartographa) } \\
\quad \text { (subg. Lygris) } \\
\quad \text { (subg. Christophiella) }\end{array}$ & Chartographa & Christophiella & $\begin{array}{l}\text { Eulithis } \\
\text { Chartographa }\end{array}$ & Eulithis \\
\hline $\begin{array}{l}\text { Eucosmabraxas } \\
\text { Gandaritis }\end{array}$ & $\begin{array}{l}\text { Eucosmabraxas } \\
\text { Gandaritis }\end{array}$ & $\begin{array}{l}\text { Eucosmabraxas } \\
\text { Gandaritis }\end{array}$ & Gandaritis & Gandaritis \\
\hline
\end{tabular}

${ }^{a}$ Prout excluded Eulithis in this study because he regarded the genus as a North American one, but later Herbulot (1964) synonymized Lygris with Eulithis.

lished, based on several synapomorphies (Choi, 1997). Prout $(1914,1938)$ first classified these larentiine genera based on a few morphological characters: male antennae, labial palps, frons, areole number of forewing, and the presence of hair-pencils. Currently the checklists of geometrid moths of Taiwan, Japan, Russia, and China, respectively, have followed Prout's classification system, but treated differently on the two genera Lobogonodes and Christophiella (table 1). The above morphological characters such as the shape of male antennae, areole number of forewing, and the presence of hair-pencils are useful in diagnosing taxa, but are found highly homoplasious. In addition, Prout had not considered the genitalia of both sexes in classifying these groups. Thus the monophyly of these genera is in question. Secondly, I trace the mimetic wing-pattern resemblance across the resulting phylogeny. Here the ingroup comprises several East Asian genera and a Holarctic genus, Eulithis. The sister relationships among these groups have not been investigated before. The mapping of wing-pattern characters onto the resulting phylogeny reveals an evolution of divergent pattern types.

\section{MATERIALS AND METHODS}

The material used in the present study was obtained from the following institutions and private collections: American Museum of Natural History, New York (AMNH); The Natural History Museum, London (BMNH); private collection of Hiroshi Inoue, Iruma (HI); Kyunghee University, Seoul (KU); National Museum of Natural History, Washington, DC. (USNM); and Zoological Museum, University of Helsinki, Helsinki (ZMU).

Permanent slide mounts (in Euparal) of the male and female genitalia were prepared. The abdomens were soaked in cold $10 \%$ $\mathrm{KOH}$ for about 24 hours, cleaned by removing scales and tissues, and stained with Chlorazol Black. The vesica of male genitalia was everted, using the general procedure of Bolte (1990). Drawings were prepared with a camera lucida attached to a Wild M5 dissecting microscope. Electron micrographs of male antennae were taken with a Hitachi S4700 Field Emission Scanning Electron Microscope (FE-SEM). Terminology for adult morphology and genitalia follows Pierce (1914), Forbes (1948), and Scoble (1992).

A cladistic analysis was done using the parsimony-based program NONA (Goloboff, 1993, version 1.5 , with the command "hold*hold/30mult*15"). The data matrix is provided in table 2. The ingroup comprised 41 species: Evecliptopera Inoue (1), Calleulype (1), Callabraxas (2), Lobogonodes Bastelberger (1), Chartographa (4), Eucosma- 
TABLE 2

Data Matrix for the Present Analysis

See Character Analysis for characters and character states.

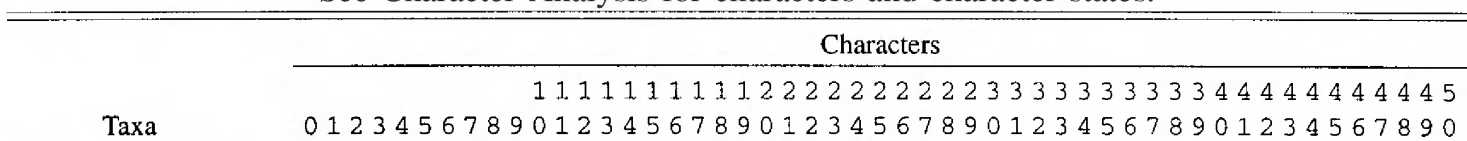

Tel. punctimarginaria

Cid. fulvata

Cer. gueneata

Lam. suffumata

Ecl. silaceata

Ecl. atricolorata

Eve, illitata

Cau. whitelyi

Cha. ludovicaria

Cha. plurilineata

Cha. compositata

Cha. fabiolaria

Cal. amanda

Cal. maculata

Euc. placida

Euc. evanescens

Gan. fixseni

Gan. agnes

Gan. sinicaria

Gan. flavomacularia

Gan. flavata

Eut. reticulatum

Eut. melancholicum

Eut. aerosum

Eut. japonicum

Eut. semiatratum

Eut. fasciatum

Eut. atrifasciatum

Lob. multistriata

Eul. testata

Eul.populata

Eul. ledereri

Eul. convergenata

Eul. diversilineata

Eul. explanata

Eul. gracilineata

Eul. molliculata

Eul. flavibrunneata

Eul. luteolata

Eul.propulsata

Eul. destinata

Eul.xylina

Eul. mellinata

Eul. prunata

Eul.pyropata

Eul.pyraliata

Eul.powellata
000000000000000000000000000000000000000000000000000 010001000000100010001020100001000000033010020000031 021200110000100110001000000100101010210010030101031 000300000000100010011020120111230000020000212000052 000300000000200010311000100001001001010000001000001 011210000000200100111011001100001002033000010000001 020210000110100010001020100101200001011000010000041 000000000000012201211120001000000001033000010000010 011010110111002211211121100101000001011010110000101 $0112111100110022104110001001010000010100 \ldots \ldots$ 000010110011012201411110110101000001011010020000101 011201110000211111311110100111000001110010100000001 011000110000202211411000001101001001010110101000001 011001000000011211011011000100011102000010100000111 010000000000010201211020001100001100033000010000011 010000000000012201211020001100001000033000110000011 010000000000110110311111001100001102033100100000011 010001000000010211211111000110.001102033010100000011 011001001000110110111110001110001102033100100000011 $0100010010000101101111110011100011020331 \ldots \ldots$ $0110010010001101101111100011100011020331 \ldots \ldots$ 011210212010100110301010100001000002033010010000011 011210210000100110411011101101000002002110001000011 011210212010100110301100100101010002202110200000011 011211210010100010301100100101011002002110110000011 010200220000100110200021000000021112010010000001121 010200220000100010200020000000021112010010000002121 011100000000000010100020000000021102010010000002121 021011110010200010201002100001101001033010010000031 121001110000100010211020101101000001011000001000011 021001110000100010211120100101000001011010001000011 021001110001200110211120101101000101011010001000152 021001110111001010211110110101000001111010001000111 121001110001101010211120101101000001010010000000001 021301110000200110311120101111001202011001010000231 121001110001101010311120101101000001000010001000001 021301113000201010211120111111000001011010111000101 021301110000200110211120101001000001011010110000052 221001110000100010311100110001000021211001130110031 021001110000201010211121100111000001111011030100011 021200110000200110211100111101000001011010100001131 221001110000201110211120100111000011011011130110052 021001110000100010311110110101001001211010231102152 021001110000201110311020101111000001210010100000152 021001110000101010211120101101000001211010110000052 021001000000100010111110001100000021001110120000011 021001000000201010311121101111000101033111100000001

Hyphens (-) indicate the missing states due to the absence of specimens. Abbreviations of genera: Tel., Telenomeuta; Cid., Cidaria; Cer., Ceratodalia; Lam., Lampropteryx; Ecl., Ecliptopera; Eve., Evecliptopera; Cha., Chartographa; Cal., Callabraxas; Cau., Calleulype; Euc., Eucosmabraxas; Gan., Gandaritis; Eut., Eustroma; Lob., Lobogonodes; and Eul., Eulithis. 
A

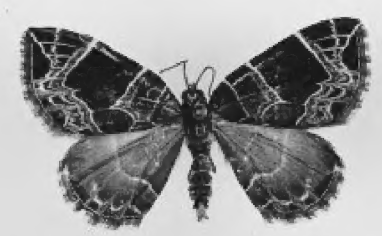

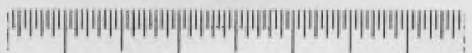

$\begin{array}{llll}13 & 14 & 15 & 16\end{array}$

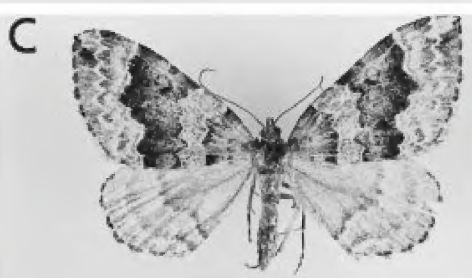

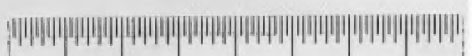
$\begin{array}{llll}13 & 14 & 15 & 16\end{array}$

E

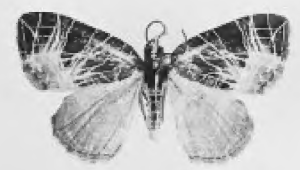

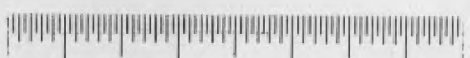
13

G

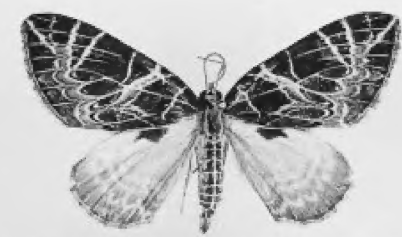

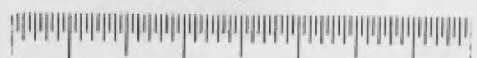

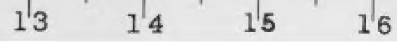

I

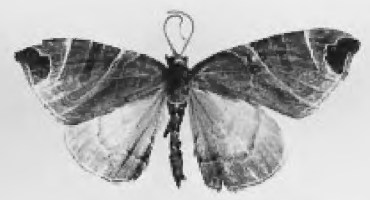

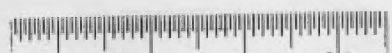
13
B

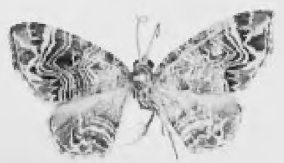

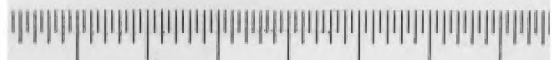

$\begin{array}{llll}13 & 14 & 15 & 16\end{array}$

D

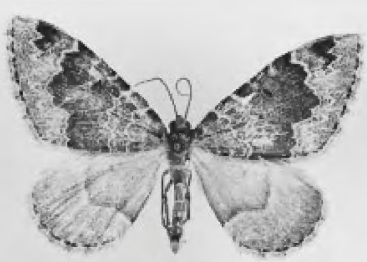

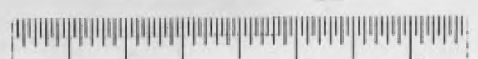
$\begin{array}{llll}13 & 14 & 15 & 16\end{array}$

F

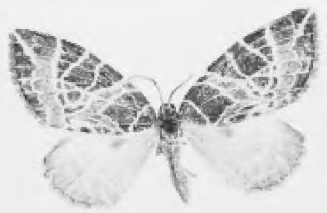

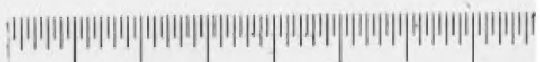
13
14
15
16

$\mathrm{H}$

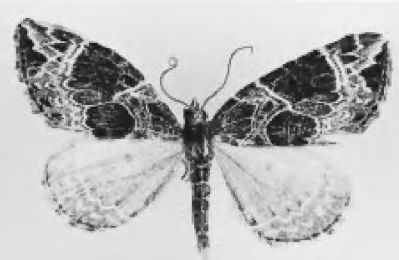

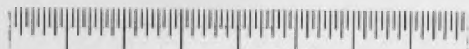

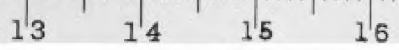

J

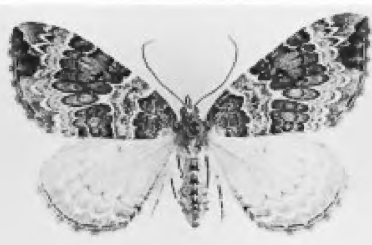

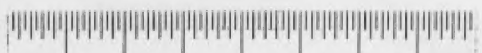

$13 \quad 14 \quad 15 \quad 16$

Fig. 2. Adults of ingroup taxa. A. Ecliptopera (= Gandaritis) atricolorata; B. Lobogonodes multistriata; C. Eustroma (= Antepirrhoe) fasciatum; D. Eustroma (= Antepirrhoe) atrifasciatum; E. Evecliptopera illitata; F. Eustroma reticulatum; G. Eustroma aerosum; H. Eustroma melancholicum; I. Eulithis ledereri; J. Eulithis explanata. 


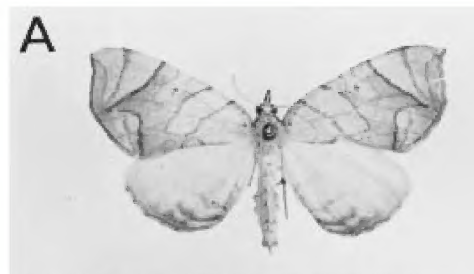

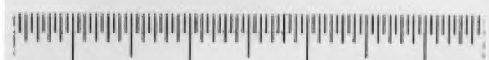
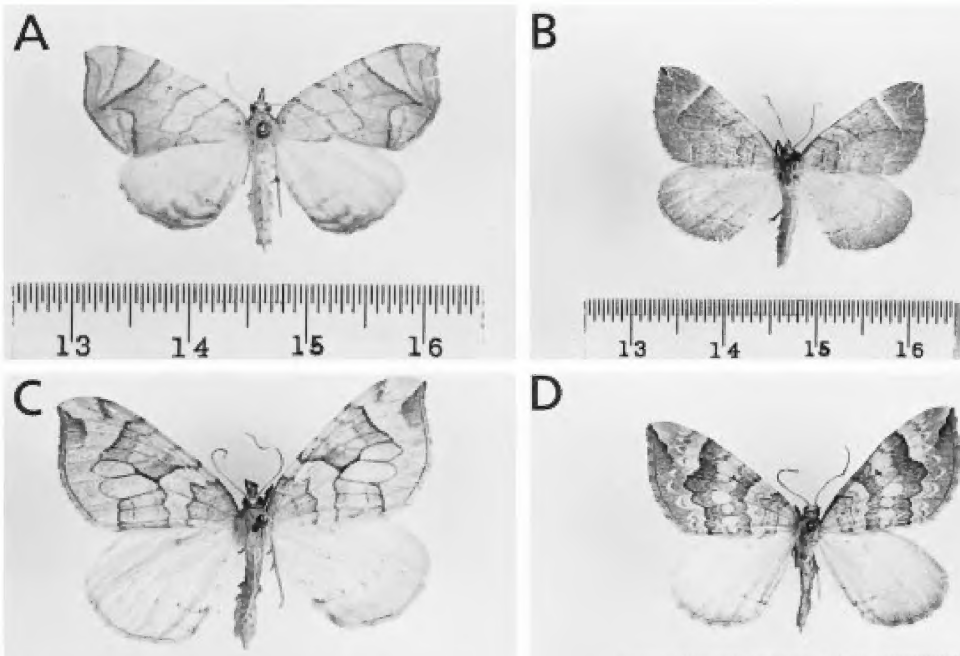

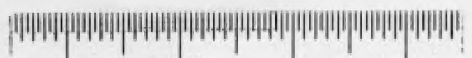

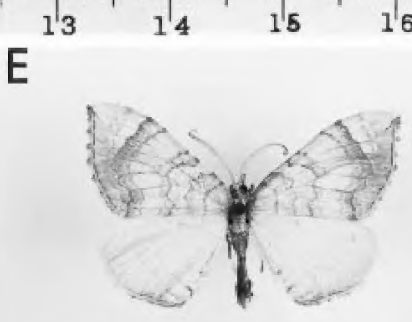

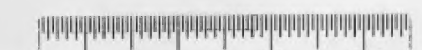

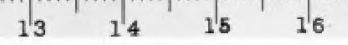

D

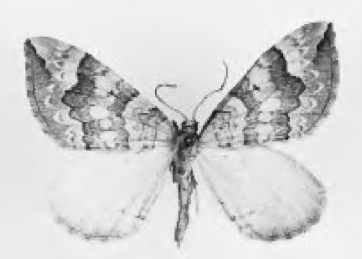

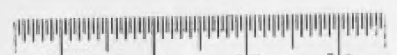

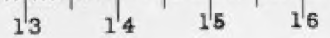

F

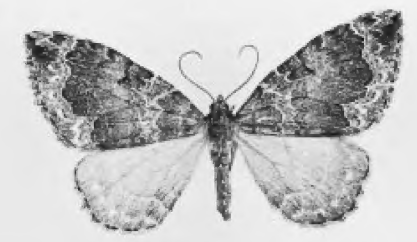

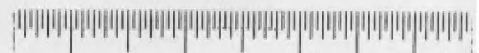
13
$14 \quad 15 \quad 16$

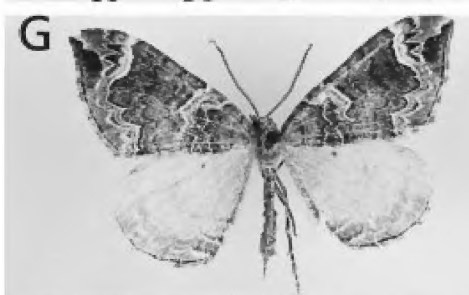

1N.

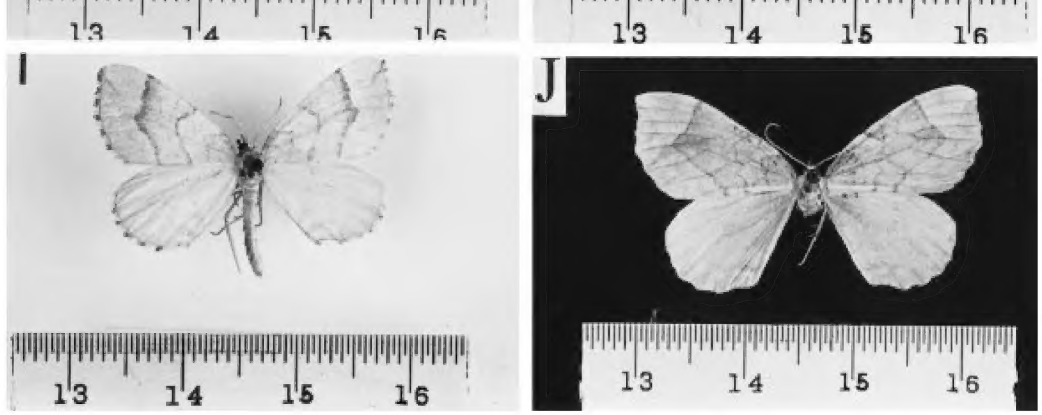

Fig. 3. Adults of ingroup taxa. A. Eulithis diversilineata; B. E. testata; C. E. propulsata; D. E. populata; E. E. luteolata; F. E. destinata; G. E. xylina; H. E. (= Gandaritis) pyraliata; I. E. mellinata; J. E. (= Gandaritis) powellata. 
braxas (2), Gandaritis (5), Eustroma Hübner (7), and Eulithis (18). Six outgroup taxa were used to root the cladograms: Telenomeuta punctimarginaria (Leech), Cidaria fulvata (Forster), Ecliptopera silaceata (Denis and Schiffermüller), E. atricolorata (Grote and Robinson), Ceratodalia gueneata Packard and Lampropteryx suffumata (Denis and Schiffermüller). The choice of outgroups was based on the close relationships as discussed in previous studies (Prout, 1914; Forbes, 1948; McGuffin, 1958). All outgroup taxa are Cidariini, although the status of Telenomeuta is uncertain. A total of 51 characters from the genitalia and other external morphological structures were analyzed. All characters, including 25 multistate characters, were treated as unordered during analyses.

Here I examined and dissected more than one male and female of each species, unless only the type specimen or a single specimen was available. In these cases the only available specimen was examined. Traditionally larentiine workers have limited their studies to the shapes of head appendages (male antennae, frons, labial palp) and of the valve and aedeagus. In the present study I consider these structures in addition to others such as the subscaphium, juxta, anellus lobe, tegumen, saccus, and vesica. Several character complexes (e.g., sexual tufts, anellus lobe, juxta, vesica, and cornuti) appeared to require more detailed study.

To trace the evolutionary pattern of mimetic characters, such as the yellowish marking at the tornus of the forewing (character 9) and distinctive marking of the postmedial line (character 13) and the tornus (character 14) of the hindwing, black dots at the termen of the hindwing (character 15), and black dots on a whitish or yellowish abdomen (character 17), I superimposed changes in these characters on the derived phylogeny using MacClade (Maddison and Maddison, 1992).

\section{RESULTS}

\section{Character Analysis}

Of the 51 characters, characters $0-5$ are from the head and thorax; 6-16 from the wing pattern; 17-39 from the abdomen and male genitalia; and 40-50 from the female genitalia.

\section{HEAD AND THORAX}

0. Male antennae: (O) filiform; (1) serrate; (2) pectinate (fig. 4). Most ingroup taxa show filiform antennae in both sexes (e.g., Eulithis populata; fig. 4E, F). Three taxa, Eulithis testata, E. diversilineata and E. gracilineata, have serrate male antennae (fig. 4A, B), and two taxa, E. luteolata and E. xylina, have pectinate male antennae (fig. 4C, D). However, females of these five taxa have filiform antennae. In addition, several Eustroma species have bipectinate male antennae (e.g., E. promachum, E. elistum).

1. Labial palp length compared to eye diameter: $(0)$ very short, less than 1.5 times eye diameter; (1) moderate, about twice eye diameter; (2) long, more than twice eye diameter. Here I measure the length of labial palp by comparing with eye diameter. The labial palps in most taxa exceed head, but the total length varies, in reference to the eye diameter. Four genera, Ceratodalia, Evecliptopera, Lobogonodes, and Eulithis, have very long labial palps, being more than twice the eye diameter, while four ingroup genera, Callabraxas, Chartographa, Eustroma, and Gandaritis, have labial palps of moderate length, about twice the eye diameter. Three outgroup taxa, Telenomeuta punctimarginaria, Lampropteryx suffumata, Ecliptopera silaceata and two ingroup taxa, Calleulype whitelyi and Chartographa compositata, have short labial palps, less than twice the eye diameter. Prout (1914) noted that labial palp length varies among genera and this length depends on the second segment. In the taxa examined here, the second segment is longer than the first segment.

2. Shape of frons: $(0)$ without projected scales at bottom; (1) projected scales present at bottom. In Cidariini, the frons shows two character states, with projected scales at bottom, or rounded (Prout, 1914; Choi, 1997). Most outgroups show the rounded frons, but Eulithis shows the frons with projected scales at bottom. These projected scales are often distinctive in their ochreous color (e.g., E. diversilineata, E. gracilineata, and E. mellinata). 

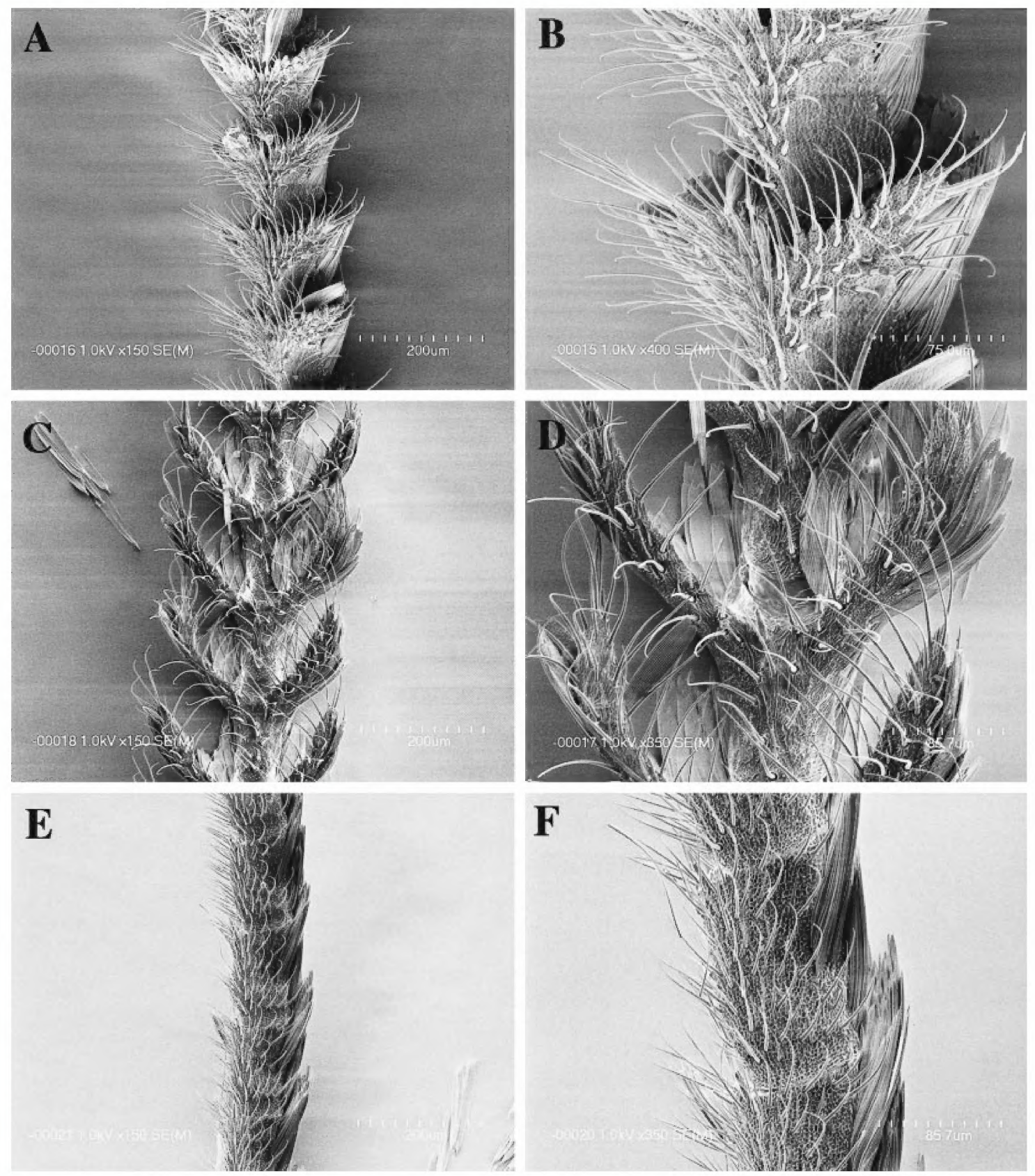

Fig. 4. Scanning electron micrographs of male antennae, ventral surface (character 0). A-B. Eulithis diversilineata; C-D. E. xylina; E-F. E. populata.

3. Color of frons: $(0)$ unicolorous scales; (1) appressed margin with differently colored scales; (2) mixed scales. The frons varies in color, e.g., dark brown, yellow, yellowish white, or ochreous. Three ingroup genera have unicolorous scales on the frons: Calla- braxas, Eucosmabraxas, and Gandaritis. Species of Eustroma are usually distinct in the shape of the frons, having V-shaped marginal scales. Species of Eulithis are divided into two states, either uniformly colored (e.g., E. testata, E. populata, E. xylina, and 
E. luteolata), or with mixed color scales (e.g., E. explanata, E. molliculata, and E. flavibrunneata).

4. Dorsum of head and thorax: $(0)$ without distinct white lines; (1) with distinct longitudinal white lines (fig. 8D). Several ingroup species bear two parallel white lines, starting from the frons to the thorax: Ecliptopera atricolorata, Evecliptopera illitata, Chartographa ludovicaria, C. plurilineata, C. compositata, Eustroma reticulatum, E. melancholicum, E. aerosum, E. japonicum, and Lobogonodes multistriata.

5. Foreleg with tibial joints: $(O)$ distinct, with yellow or black scales; (1) indistinct, being same color as scales on rest of leg. The tibial joints of the foreleg are distinctive in several taxa: Chartographa ludovicaria, C. compositata, Calleulype whitelyi, Eucosmabraxas, and Eustroma. However, most species of Eulithis and Gandaritis exhibit tibial joints that are concolorous with forelegs.

\section{WINGS}

6. Male forewing with ventral sexual tufts: (0) absent; (1) present, originating from the anal vein; (2) present, originating between anal vein and inner margin.

7. Sexual tufts: (O) fan-shaped; (1) long, thin. Sexual tufts are variable in color (black, yellowish white, or ochreous) and shape (fan-shaped or thin, long). Most ingroup taxa, Eulithis, Eustroma, Lobogonodes, and Chartographa, have diverse sexual tufts on the underside of the forewing, but differ in the position of the base of these hairs, either on the anal vein or between anal vein and inner margin. Species of Eustroma bear blackish hairs originating between anal vein and inner margin, while the species of $\mathbf{E u}$ lithis and Chartographa have yellowish hairs originating from the anal vein. Usually one kind of hairs is present, but three groups of hairs occur in Eustroma melancholicum. Sexual tufts on the underside of forewing direct toward costad, except on one species, Lobogonodes multistriata, direct toward forewing inner margin. Two Eulithis, E. pyraliata, E. powellata, and few ingroup genera, Calleulype, Evecliptopera, Eucosmabraxas, and Gandaritis, lack sexual tufts. Eustroma atrifasciata and Callabraxas maculata bear no sexual tufts. Forbes (1948) described Eulithis having fan-shaped tufts, but Eustroma from North America (E. semiatratum, E. fasciatum) having slender, black, line tufts.

8. Sexual dimorphism: (0) absent; (1) exhibited as mark on forewing; (2) present on discoidal dot of hindwing; (3) exhibited in wing coloration. Prout (1914) noted that two Gandaritis species ( $G$. sinicaria and $G$. flavata) have a sexual mark on the upper side of the forewing. A few Eustroma species show sexual dimorphism in the discoidal dot of the hindwing. For example, E. reticulatum males have a discoidal dot that is orange, whereas the female discoidal dot is black. Males of E. aerosum are distinct in having a large, triangular, black, discoidal dot on the upperside of the hindwing, but its relatives E. inextricatum and E. japonicum lack this discoidal dot. In addition, $E$. reticulatum shows a sexual marking on the underside of the forewing. One species of Eulithis, E. molliculata, shows sexual dimorphism in wing ground color: males are brownish and females are yellowish.

9. Yellow marking on the tornus of forewing: (0) absent; (1) present (fig. 8B). This feature is seen in the model, Abraxas. Five species of the ingroup, Evecliptopera illitata, Chartographa ludovicaria, C. plurilineata, Calleulype whitelyi, and Eucosmabraxas placida, similarly have yellow markings on the tornus of the forewing.

10. Wing pattern elements in forewing: (O) banded (fig. 8A, C); (1) linear (fig. 8B, D). Species of Larentiinae are usually distinctive in their contrasting central fascia in color and pattern. However, the central fascia in some species is obscure due to numerous transverse lines and is here coded as linear, for their wing pattern elements: Evecliptopera illitata, Chartographa ludovicaria, C. plurilineata, C. compositata, Eustroma reticulatum, E. aerosum, E. japonicum, Lobogonodes multistriata and Eulithis convergenata.

11. Orientation of forewing fascia: $(O)$ vertical (fig. 8C); (1) diagonal (fig. 8B). The central fascia of most species is vertical, meeting inner margin in the middle of the wing. The central fasciae of seven ingroup taxa run toward the tornus of the forewing and are here coded as diagonal fasciae: Char- 


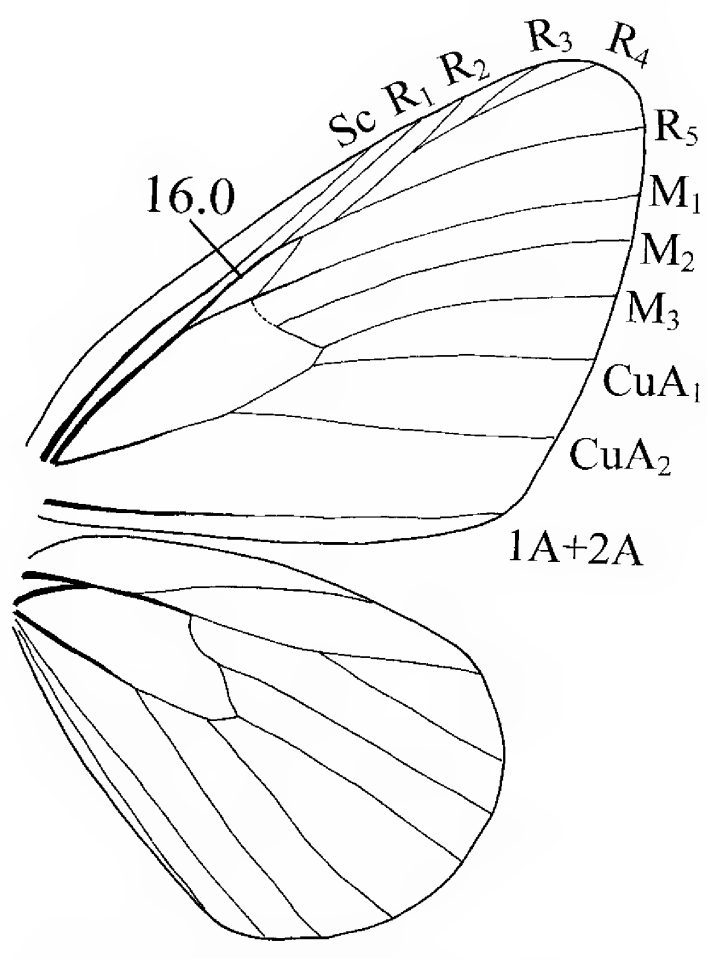

Fig. 5. Wing venation of Calleulype (= Gandaritis) whitelyi. Scale bar $=1 \mathrm{~mm}$.

tographa ludovicaria, C. plurilineata, $C$. compositata, Eulithis ledereri, E. convergen$a t a, E$. diversilineata and $E$. gracilineata.

12. Apical streak on forewing: (0) $a b$ sent; (1) present (fig. 8C); (2) present as an apical blotch. A distinct apical streak is observed in Gandaritis, Eustroma, Evecliptopera, and some Eulithis (E. diversilineata, $E$. gracilineata, E. luteolata, E. mellinata, E. pyraliata). A triangular apical blotch is observed in Ecliptopera, Callabraxas, Lobogonodes, and several Eulithis species (E. ledereri, E. explanata, E. molliculata, E. destinata).

13. Shape of postmedial line of hindwing: $(0)$ simple, thin line $(s) ;(1)$ prominent, waved and black dots (fig. 8C). The postmedial lines of the hindwing are variable in their number and shape: one or two; waved or transverse. The postmedial lines of two taxa, Telenomeuta punctimarginaria and Lobogonodes multistriata, consist of several transverse lines. The postmedial lines of Chartographa, Calleulype, Callabraxas, Eu-

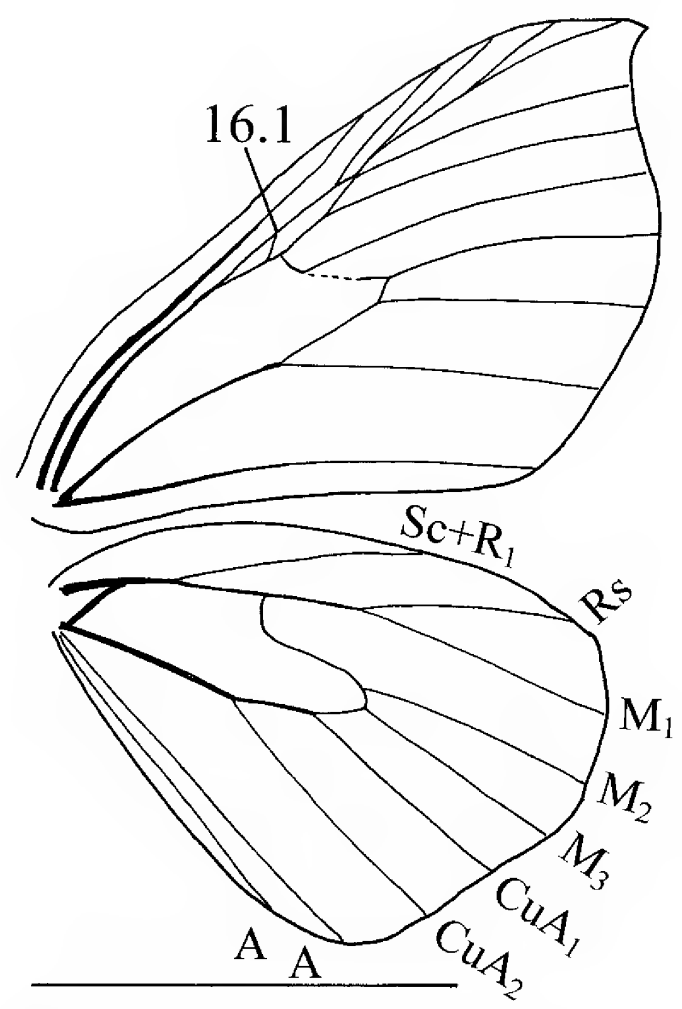

Fig. 6. Wing venation of Eulithis diversilineata. Scale bar $=1 \mathrm{~mm}$.

cosmabraxas, and Gandaritis are distinguished by being thick, waved, and having black dots. A distinct postmedial line of the hindwing also occurs in Abraxas.

14. Tornus of hindwing: $(O)$ not distinct, like rest of the wing; (1) tinged with blackish waved lines; (2) tinged with yellowish markings (fig. 8B). The tornus of hindwing in many Eulithis are distinct in having blackish terminal lines that only appear at the tornus and do not extend to the termen (e.g., Ecliptopera atricolorata, Eulithis convergenata, E. diversilineata, and E. xylina). Many Asian species have distinct yellowish or brownish markings with black dots (Callabraxas amanda, C. maculata, Chartographa ludovicaria, C. plurilineata, C. compositata, C. fabiolaria, and Calleulype whitelyi).

15. Termen of hindwing: $(0)$ indistinct subterminal line; (1) with waved subterminal line (fig. 8A, D); (2) with large, black dots (fig. 8B, C). In Gandaritis, Eustroma (E. reticulatum, E. melancholicum, E. semiatra- 


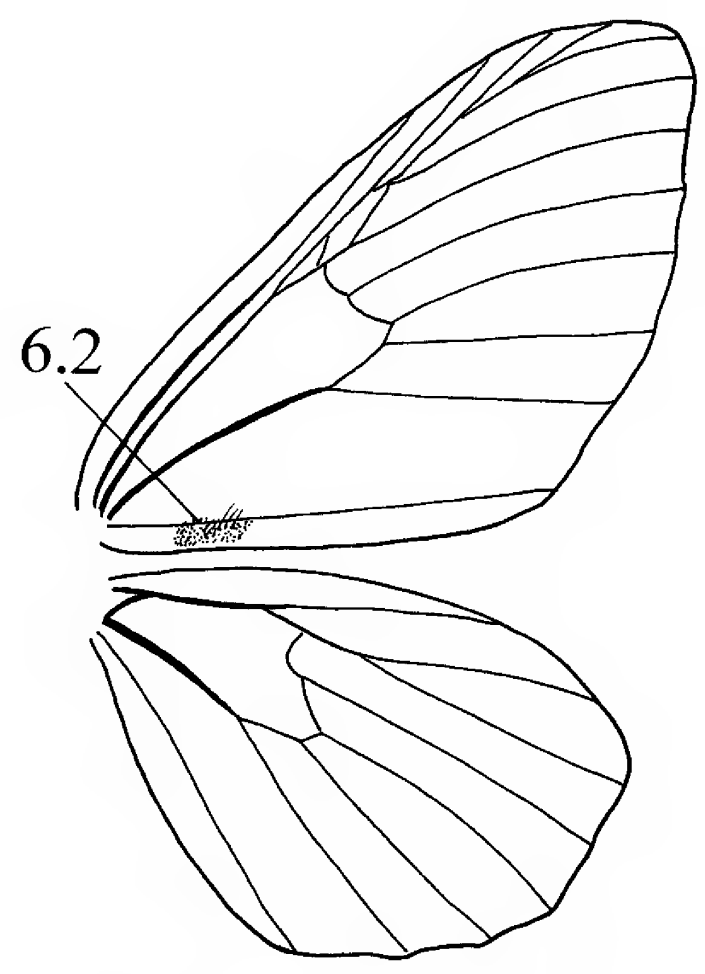

Fig. 7. Wing venation of Eustroma (= Antepirrhoe) semiatratum. Scale bar $=1 \mathrm{~mm}$.

tum) and Eulithis (E. ledereri, E. explanata, $E$. destinata, E. xylina), the termen has a waved subterminal line, although the subterminal line of Gandaritis is frequently distinguished from that of Eustroma and Eulithis by being thick and more blackish. Many pairs of black dots at the termen, a feature occurring in Abraxas, are observed in the species of Chartographa, Callabraxas and Eucosmabraxas.

16. Areole number in forewing: (0) one; (1) two (figs. 5-7). In the forewing an areole is formed between veins $R_{1}$ and $R s$, and the number of areoles varies from one to two (Scoble, 1992). Two outgroup, Telenomeuta punctimarginaria and Ecliptopera atricolorata, and four ingroup taxa, Calleulype whitelyi, Chartographa compositata, Eucosmabraxas placida, and $E$. evanescens, have one areole in the forewing (fig. 5). It should be noted that the number of areoles is variable in some taxa. For example, Prout (1914) noted that the areole in Chartographa compos- itata varies from one to two. Most taxa have two areoles (figs. 6-7).

\section{Abdomen and Male Genitalia}

17. Abdomen: (O) without distinguishing black dots; (1) with distinguishing black dots on yellow abdomen. In many the abdomen is the same color as the thorax: brown, yellow, or ochreous. Sometimes the abdomen is distinguished by pairs of black dots on white or yellow ground color; this feature is also observed in the model, Abraxas. The taxa that exhibit this feature are Chartographa ludovicaria, C. compositata, C. fabiolaria, Calleulype whitelyi, Callabraxas amanda, C. maculata, Eucosmabraxas placida, E. evanescens, and Gandaritis agnes.

18. Shape of eighth sternite: $(O)$ anterior margin wider than posterior; (1) slender and uniform in width; (2) broad and uniform in width; (3) posterior margin wider than anterior and posterior edges not sharply pointed; (4) posterior margin wider than anterior and both edges of posterior sharply pointed (fig. 9). The eighth male sternite is variable in shape. It is wider anteriorly in the outgroup taxa Telenomeuta puntimarginaria, Cidaria fulvata, and Lampropteryx suffumata (fig. 9A), and Callabraxas maculata. Species of Eulithis and Gandaritis have a slender or broad sternite (fig. 9B, C), while species of Eustroma have the posterior margin wider. The most striking feature, wider posteriorly with sharply pointed edges, is observed in four species: Chartographa plurilineata, $C$. compositata, Callabraxas amanda, and Eustroma melancholicum (fig. 9E).

19. Subscaphium: (O) membranous, indistinct; (1) distinct, with sclerotized bands. In many taxa the subscaphium is a pair of sclerotized bands (e.g., fig. 12C). Three genera, Evecliptopera, Eustroma, and Lobogonodes, have a membranous subscaphium without a sclerotized band.

20. Tegumen: (0) dome-shaped; (1) triangular. Based on the thickness of the inner ring of tegumen and the pedunculi, the shape of the tegumen is divided into two: domeshaped or triangular. Three Eustroma species from North America (E. semiatratum, E. fasciatum, and E. atrifasciatum) have a domeshaped tegumen that looks ample medially 

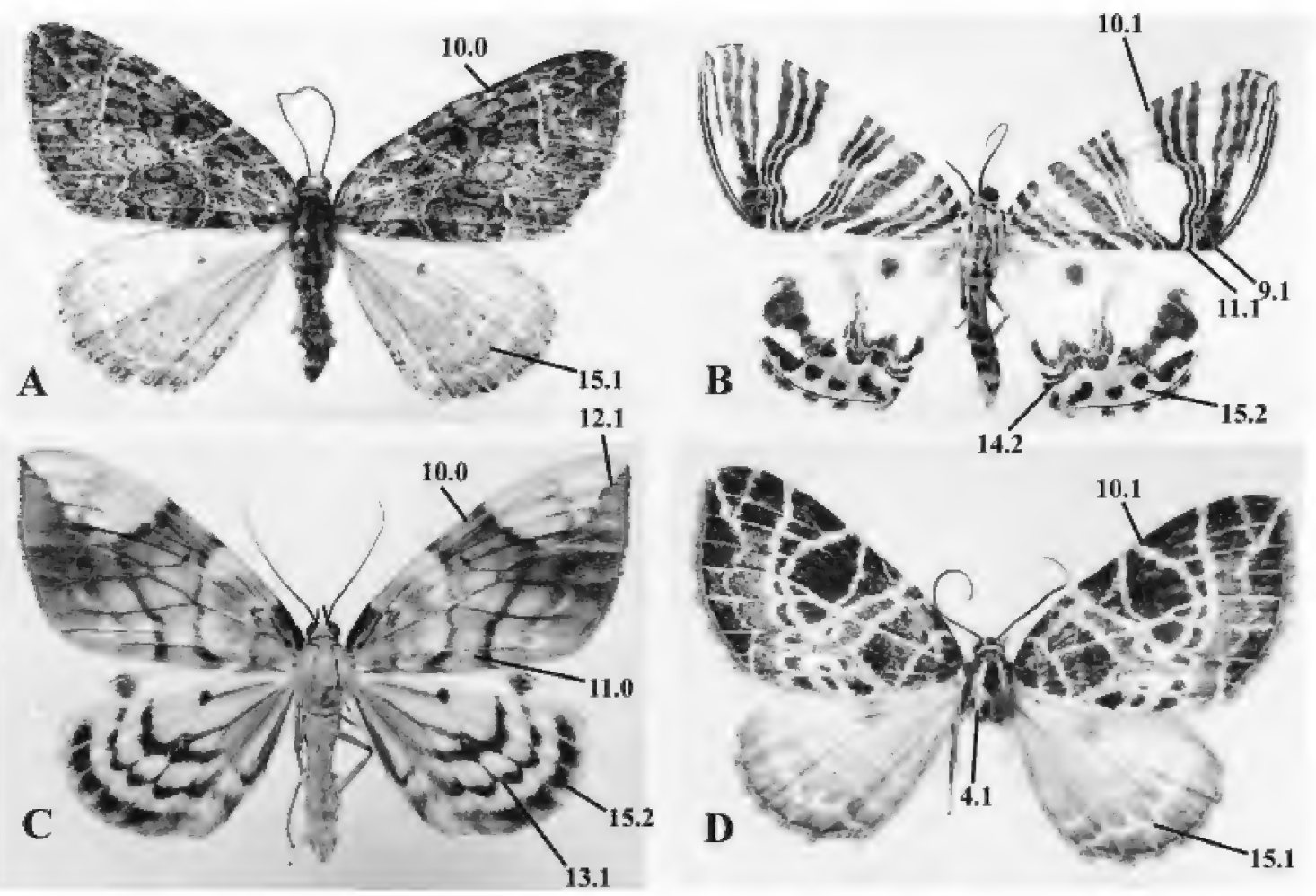

Fig. 8. Wing pattern elements of ingroup. The drawings are not to scale. Numbers indicate character and character state. A. Eustroma melancholicum; B. Chartographa (= Callabraxas) compositata; C. Gandaritis fixseni; D. Eustroma reticulatum.

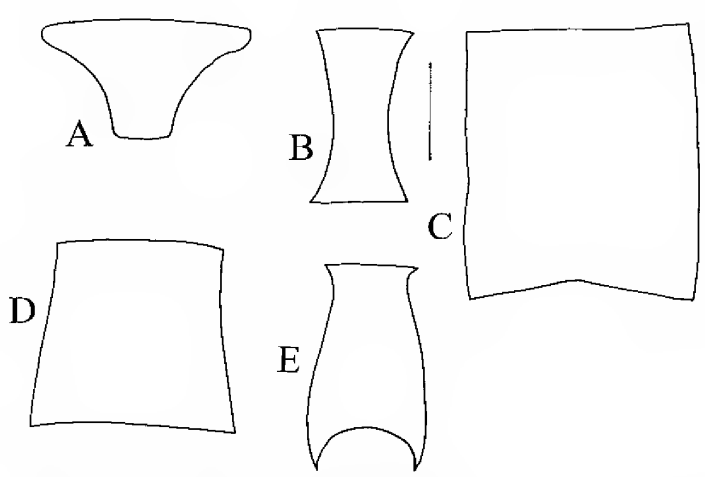

Fig. 9. Eighth male sternite, anterior margin at top. Scale bar $=1 \mathrm{~mm}$. A. Telenomeuta punctimarginaria; B. Eulithis (= Gandaritis) pyraliata; C. Gandaritis agnes; D. Chartographa (= Callabraxas) fabiolaria; E. Eustroma melancholicum. and meets the top of the vinculum obliquely due to the thin inner ring of tegumen and orthogonal pedunculi (fig. 10C). However, most ingroup taxa have a triangular tegumen due to the tapering inner ring and wide-angled pedunculi.

21. Diaphragma (fultura inferior): $(O)$ membranous; (1) scobinate. The scobinate fultura inferior is observed in most species of Gandaritis, Chartographa, Eustroma and Eulithis (e.g., fig. 12E).

22. Saccus: $(O)$ long, medially projected: (1) long, rounded; (2) short, rounded. Here I divide the saccus into three states. The length of saccus is measured against the vinculum length, and a long saccus indicates more than half as long as the vinculum. Species of Eustroma and Gandaritis have long and either rounded or medially projected saccus. Species of Eulithis show all types of saccus: long, medially projected (e.g., E. luteo- 

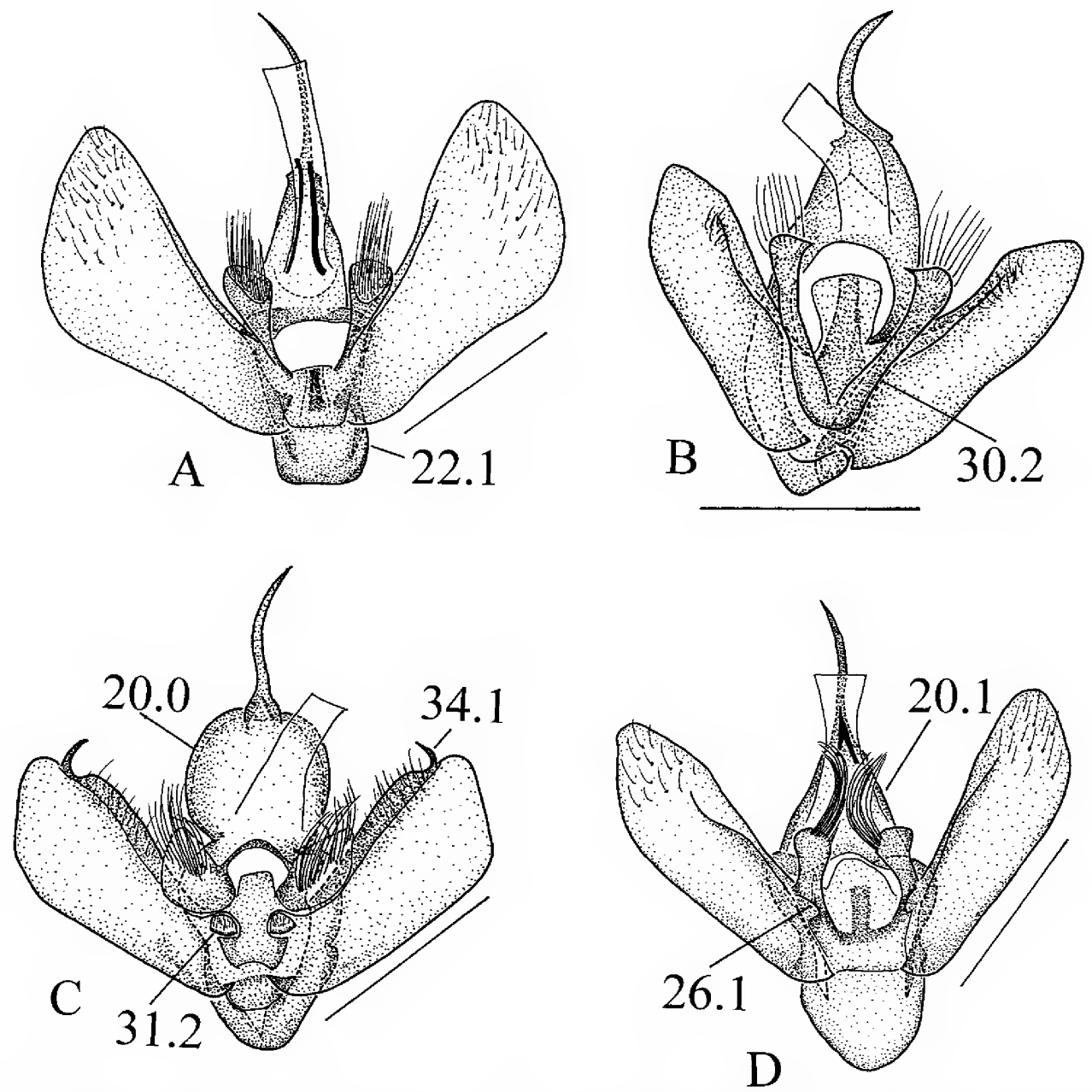

Fig. 10. Male genital capsule. Scale bar $=1 \mathrm{~mm}$. A. Ecliptopera (= Gandaritis) atricolorata; B. Evecliptopera illitata; C. Eustroma (= Antepirrhoe) semiatratum; D. Eustroma melancholicum.

lata, E. destinata; fig. 12D); long, rounded (e.g., E. convergenata, E. mellinata); or short, rounded (e.g., E. testata, E. populata, E. ledereri, E. explanata, E. powellata; fig. 12C).

23. Saccus process: (0) absent; (1) present, but small; (2) present, long. Lobogonodes multistriata has a derived character in the saccus that shows a pair of long processes projecting anteriorly (fig. 12A). Several species of Eustroma ( $E$. melancholicum, $E$. semiatratum), Callabraxas (C. maculata) and Gandaritis (G. fixseni, G. agnes, G. flavomacularia) show relatively small anterior processes on the saccus (fig. 12E).

24. Anellus lobe: $(0)$ expanded; (1) digi- tate. In the Cidariini the anellus lobe is distinct in its shape and length (Choi, 1997). Several ingroups have the anellus lobe apically expanded; Calleulype, Eucosmabraxas, Callabraxas, Gandaritis, Eustroma from North America, and Eulithis pyraliata (fig. 12B), whereas the remaining species are coded as having a digitate anellus lobe (fig. 12E). Lobogonodes has a bilobed anellus lobe, being separated in the apical part.

25. Basal part of anellus lobe: $(0)$ without processes; (1) with one pair of processes (fig. 12C); (2) with two pairs of processes.

26. Basal part of anellus lobe: $(O)$ not narrowed; (1) narrowed (fig. 10D). In most ingroup taxa the basal part of the anellus lobe 

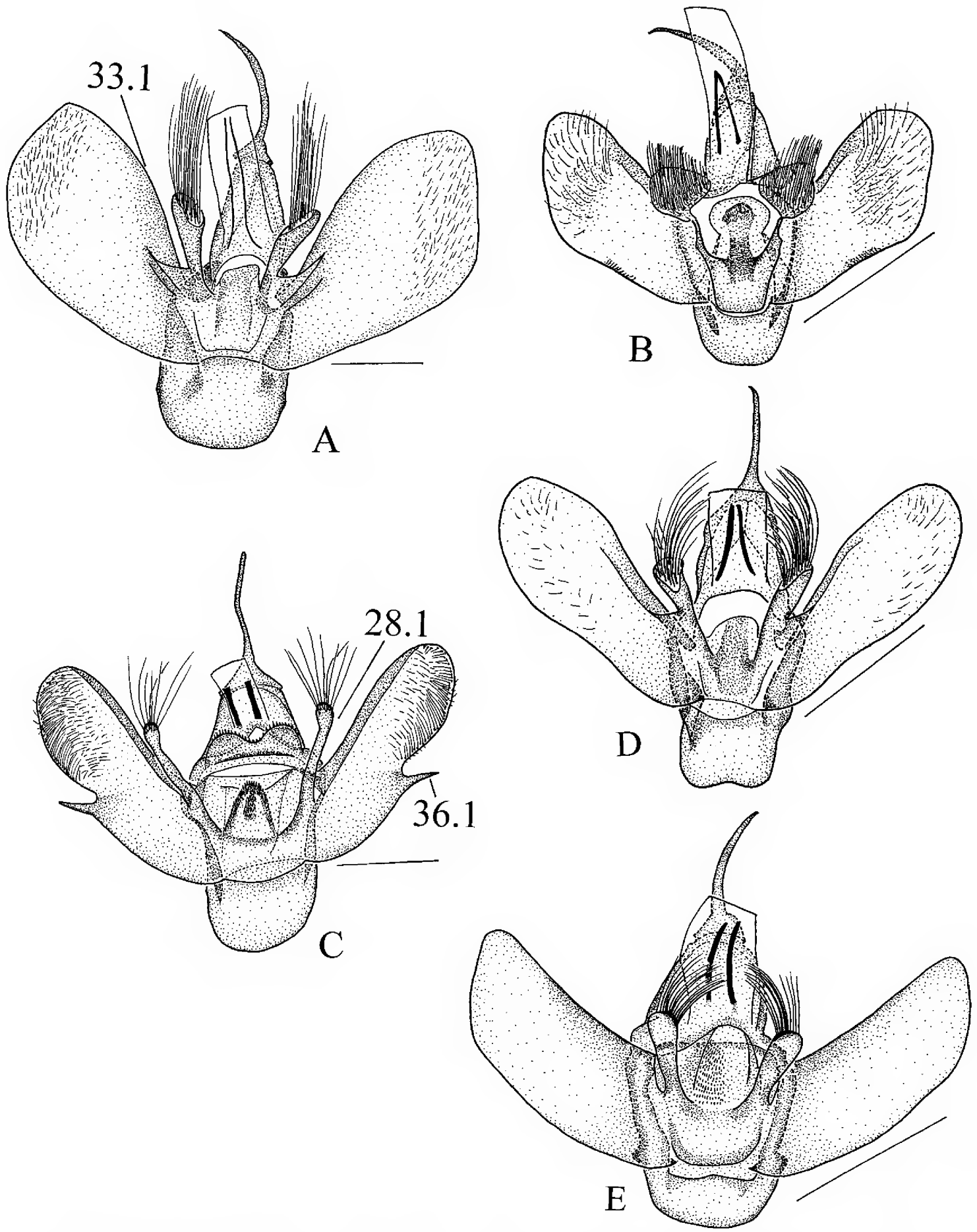

Fig. 11. Male genital capsule. Scale bar $=1 \mathrm{~mm}$. A. Gandaritis sinicaria; B. Calleulype (= Gandaritis) whitelyi; C. Chartographa (= Callabraxas) fabiolaria; D. Callabraxas (= Gandaritis) maculata; E. Chartographa (= Callabraxas) ludovicaria. 


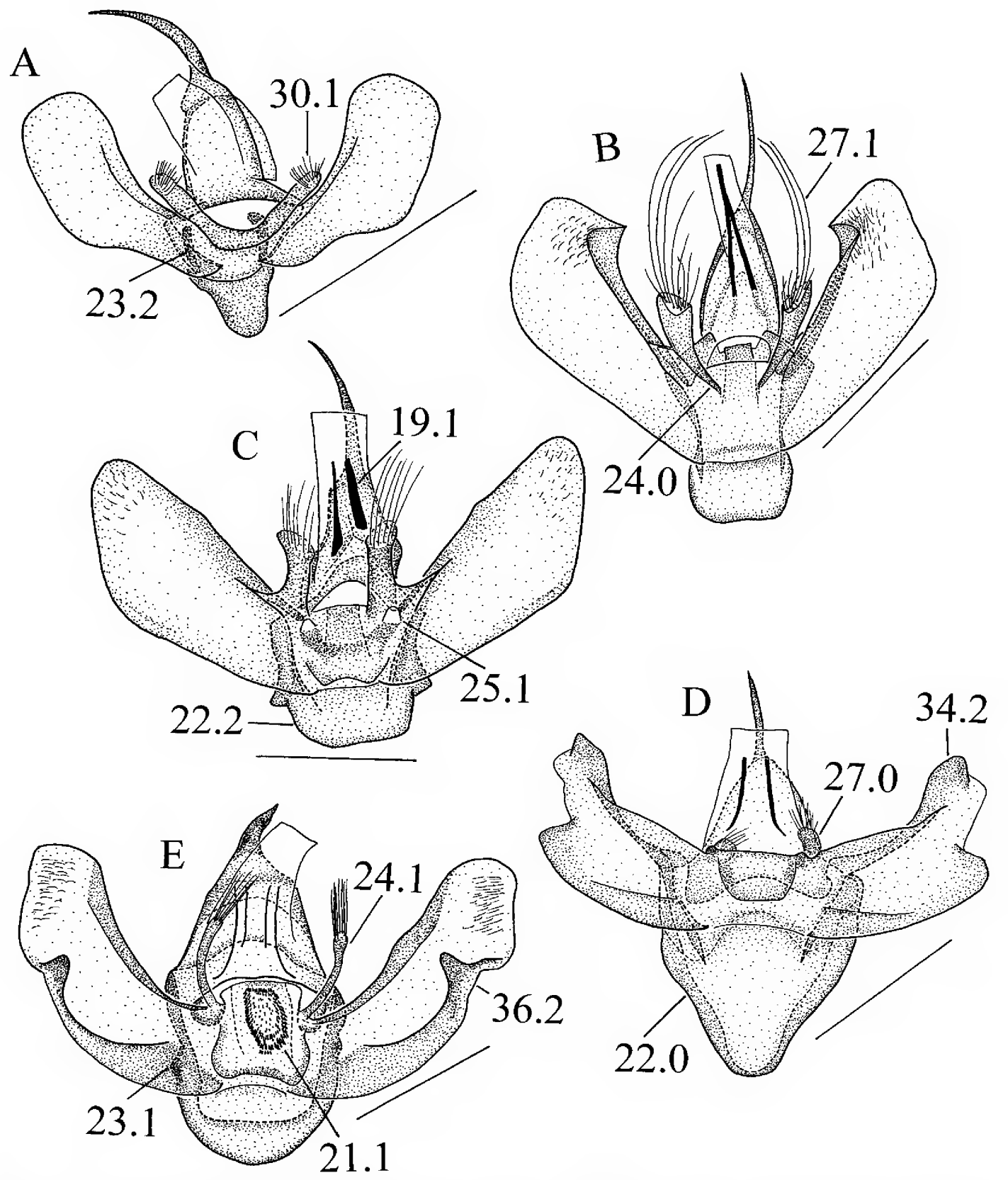

Fig. 12. Male genital capsule. Scale bar $=1 \mathrm{~mm}$. A. Lobogonodes multistriata; B. Eulithis $(=$ Gandaritis) pyraliata; C. E. (= Gandaritis) powellata; D. E. luteolata; E. E. propulsata.

has been modified in several ways: the presence of processes (character 25), being narrowed (character 26), and with spines (character 31). Species of Chartographa and Eulithis have one pair of small processes (e.g., C. compositata, E. convergenata, E. molliculata). The basal part of the anellus lobe merges into the costa of the valva, and species of Eucosmabraxas, Gandaritis, and Eulithis show the narrowed basal part of the anellus lobe.

27. Anellus lobe hairs: (0) short, not reaching uncus; (1) long, reaching uncus. The hairs on the anellus lobe are distinctive 
in length and density. Some taxa have short hairs (e.g., Calleulype whitelyi, Eustroma reticulatum, E. fasciatum, E. semiatratum, Eulithis luteolata, and E. flavibrunneata), but most other ingroups have long anellus lobe hairs, reaching bottom of the uncus (fig. 12B). Forbes (1948) described Eulithis as having a long anellus lobe with hairs at the tip.

28. Anellus lobe length: $(O)$ short, not exceeding half the length of tegumen; (1) long, exceeding half the length of tegumen. Several taxa of Gandaritis and Eulithis have a long anellus lobe that exceeds half the length of tegumen (fig. 11C): Gandaritis sinicaria, G. flavata, G. flavomacularia, G. agnes, Eulithis explanata, E. propulsata, E. xylina, E. prunata, and E. powellata. Chartographa ludovicaria and Lampropteryx suffumata have a long anellus lobe.

29. Hairs of anellus lobe: $(O)$ present on broad apical part (fig. 11B); (1) present on arm and apical parts. In the ingroup, the anellus lobe hairs are placed on the arm and the apical part of the anellus lobe (Eustroma, Chartographa, Eulithis), on a broad, rectangular, apical part (Calleulype whitelyi), or on a triangular-shaped, apical part (Eucosmabraxas, Gandaritis, Ecliptopera atricolorata, and Eulithis pyraliata).

30. Connection between juxta and anellus lobe: (O) indistinct; (1) U-shaped (fig. 12A); (2) V-shaped (fig. 10B). Sometimes the connection between the juxta and the anellus lobe is distinct, due to sclerotization. Lobogonodes multistriata has a wide, U-shaped, sclerotized connection between the juxta and the anellus lobe, while Evecliptopera and an outgroup, Lampropteryx suffumata, have a V-shaped connection.

31. Juxta: (O) without spines; (1) with spines; (2) with spines on the hole (fig. 10C); (3) with spines on the processes. The juxta of a few ingroup taxa has thin, hairlike spines (e.g., Callabraxas maculata). Two Eustroma species, E. aerosum and E. japonicum, have spines on the juxta, and three Eustroma species from North America have a pair of holes on the juxta with spines present on each hole. Lampropteryx suffumata has spines at the processes on the juxta.

32. Valva: (0) parallel-sided; (1) wider distally. Most species have a membranous valva without sclerotization or modification. The shape of the valva is divided into two states; parallel-sided or wider distally. The species of Evecliptopera, Chartographa, Calleulype, Eustroma, and Eulithis have a parallel-sided valva without expansion in the distal part. Species of Callabraxas, Eucosmabraxas, Gandaritis, Lobogonodes, and two Eulithis (i.e., E. explanata and E. mellinata) have a distally widened valva.

33. Costa: (O) without a medial expansion; (1) slightly expanded medially (fig. 11A); (2) with a medial process. The shape of costa varies from simple to medially slightly expanded, or to having a medial process. The costa of Eucosmabraxas, Callabraxas, and Gandaritis is medially slightly expanded, and that of Eustroma semiatratum, E. fasciatum, and E. atrifasciatum is sclerotized with a medial expansion. A single species, Eulithis mellinata, has a large, medial process on the costa.

34. Costa with distal process: $(0)$ absent; (1) present, sharply pointed (fig. 10C); (2) present and rectangular (fig. 12D). Four North American taxa (Ceratodalia gueneata, Eustroma semiatratum, E. fasciatum and Eulithis xylina) have a sharply pointed process at the end of costa. Two Eulithis (E. luteolata and $E$. pyraliata) have a particularly large, rectangular process.

35. Distal end of valva: $(0)$ rounded; (1) oblique; (2) vertical. The distal end of valva is divided into three states: Eucosmabraxas with a rounded end; Evecliptopera, Eulithis, Callabraxas amanda, Chartographa, and Calleulype with an oblique end; and Gandaritis, Callabraxas maculata, and Eustroma with a straight and vertical end. The distinction between oblique and vertical is observed by the different length of ventral and dorsal parts of valva; it is oblique when dorsal part is longer than ventral, and is vertical when dorsal and ventral parts have nearly the same length.

36. Saccular process: $(0)$ absent; (1) present in the middle of valva (fig. IIC); (2) present at the end of valva (fig. 12E). In most species the saccular process is absent, whereas several ingroup taxa have a process. I divided this process into two states based on its position (median vs. distal). Chartographa fabiolaria, Eulithis convergenata, and E. 

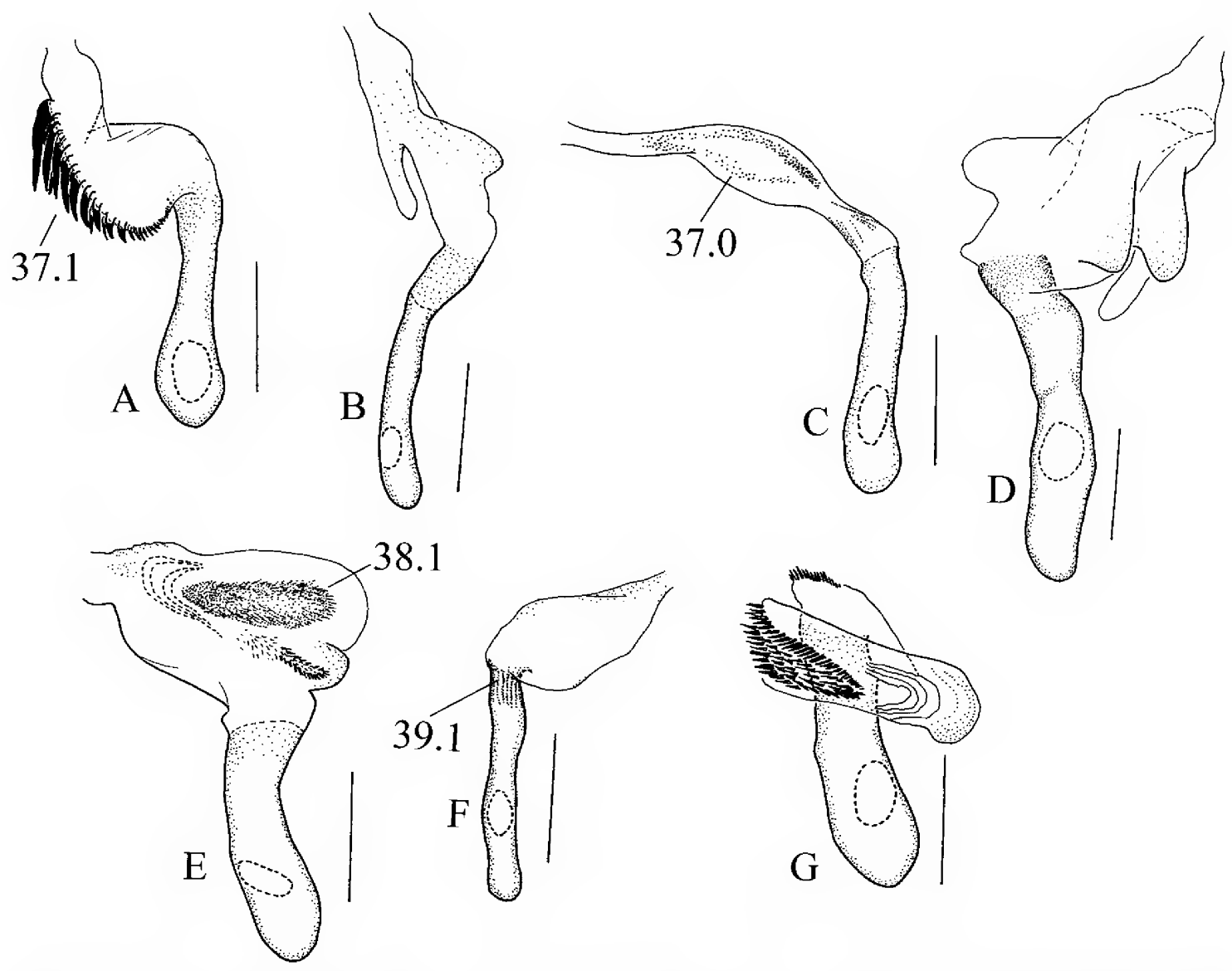

Fig. 13. Male aedeagus. Scale bar $=1 \mathrm{~mm}$. A. Eustroma (= Antepirrhoe) semiatratum; B. Ecliptopera (= Gandaritis) atricolorata; C. Eustroma aerosum; D. Gandaritis sinicaria; E. Chartographa (= Callabraxas) ludovicaria; F. Eulithis (= Gandaritis) powellata; G. E. explanata.

propulsata have a process that occurs in the middle of the valva; Eustroma aerosum, Eulithis luteolata, E. mellinata, E. prunata, and $E$. pyropata have a process at the end of the valva.

37. Cornutus (fig. 13): (0) minute setae; (1) spinular; (2) long, band-shaped; (3) absent. All outgroup and many ingroup taxa have cornuti on the vesica, but several genera and two species, Calleulype, Eucosmabraxas, Gandaritis, and Lobogonodes, Ecliptopera atricolorata and Eustroma reticulatum, lack a cornutus. The shape of the cornuti is usually spinular within the ingroup, but in the species Callabraxas maculata, Eustroma melancholicum, E. aerosum, E. japonicum, Eulithis gracilineata, and E. pyraliata, cornuti are reduced to minute setae. Lamprop- teryx suffumata has a cornutus that is in the shape of a long band.

38. Arrangement of cornuti: $(0)$ one patch; (1) two patches (fig. 13E); (2) spread on vesica; (3) cornuti absent. Cornuti are arranged into one or several groups or are absent. Three species of Eustroma from North America, Chartographa plurilineata, and Callabraxas maculata have a single cornutus patch. Most species of Eulithis, Chartographa ludovicaria, and C. compositata have two patches. Three Eustroma (E. melancholicum, E. aerosum, and E. japonicum) show no distinct patches of cornuti on the vesica and I coded this as being spread over the vesica.

39. Vesica neck: $(0)$ indistinct; (1) distinct with sclerotized lines (fig. 13F). Gandaritis, 


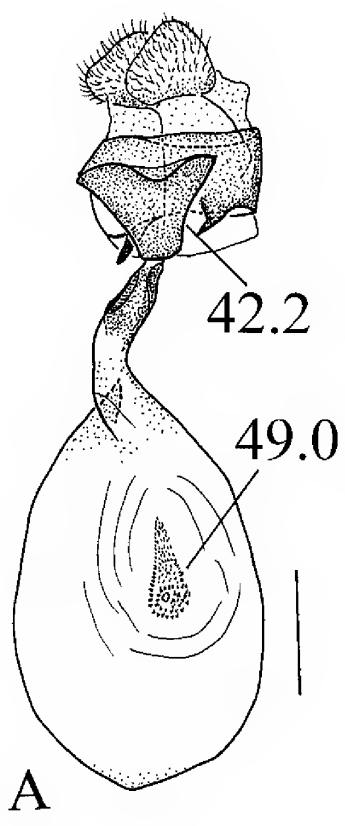

B

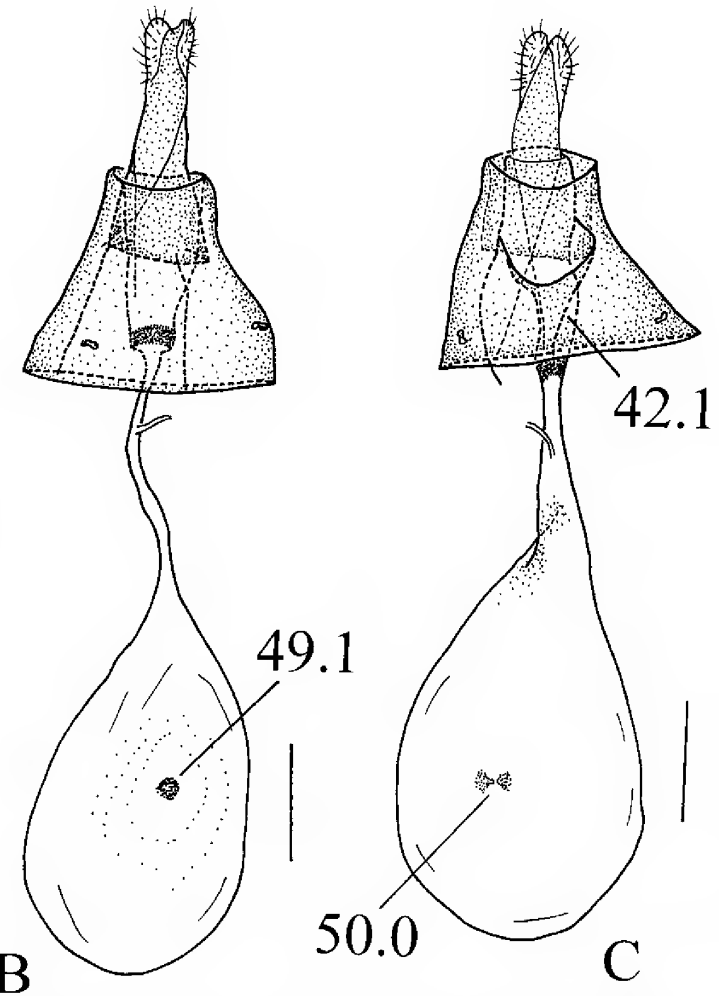

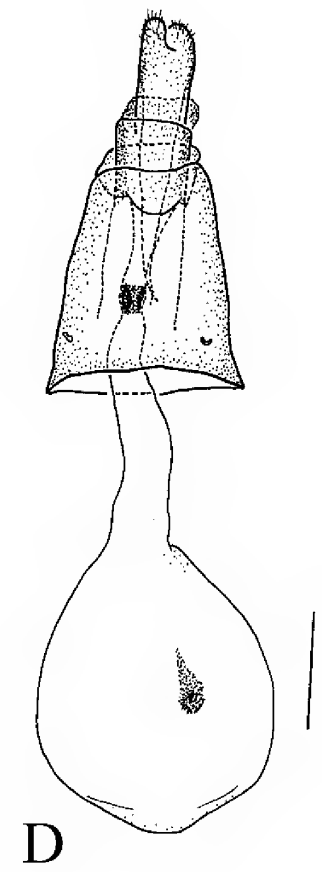

Fig. 14. Female genitalia. Scale bar $=1 \mathrm{~mm}$. A. Eustroma aerosum; B. Eucosmabraxas (= Gandaritis) evanescens; C. Calleulype (= Gandaritis) whitelyi; D. Ecliptopera (= Gandaritis) atricolorata.

Eustroma, Eulithis pyraliata, and E. powellata show a distinct vesica neck with sclerotized lines.

\section{Female Genitalia}

40. Lamella antevaginalis: $(0)$ with thin, sclerotized band (fig. 15B); (1) without thin band. The lamella antevaginalis is distinct having a thin sclerotized band in Evecliptopera, Calleulype, Eucosmabraxas, Gandaritis, and three species of Eulithis (E. testata, E. explanata, and E. luteolata). This feature is also observed in several outgroups: Telenomeuta, Lampropteryx, and Ecliptopera.

41. Ostium bursae: $(O)$ indistinct, membranous; (1) distinct with sclerotization. Four North American Eulithis species (E. explanata, E. luteolata, E. propulsata, and $E$. xylina) have a sclerotized ostium bursae.

42. Antrum: (O) straight; (1) funnelshaped and membranous (fig. 14C); (2) funnel-shaped and strongly sclerotized (fig. 14A). The shape of the antrum is divided into funnel-shaped or straight. The funnel-shaped antrum is observed in several taxa: Callabraxas maculata, Chartogrpha ludovicaria, Gandaritis, Eustroma (E. aerosum, E. japonicum), Eulithis (E. mellinata, E. prunata, E. pyropata, E. pyraliata). The funnel-shaped antra of Lampropteryx suffumata and Eustroma aerosum are further distinguished by heavy sclerotization. The antrum of Eulithis mellinata is sclerotized, but the shape is long and more or less triangular.

43. Position of colliculum in ductus bursae: (0) close to corpus bursae; (1) close to antrum; (2) in the middle of ductus bursae; (3) colliculum absent. The position of a colliculum varies in the ductus bursae. One outgroup and four Eulithis (Ceratodalia gueneata, E. luteolata, E. propulsata, E. xylina, E. mellinata) have no colliculum.

44. Length of ductus bursae compared to seventh segment: $(0)$ nearly equal; (1) shorter; (2) twice as long as seventh segment. The length of the ductus bursae is mea- 

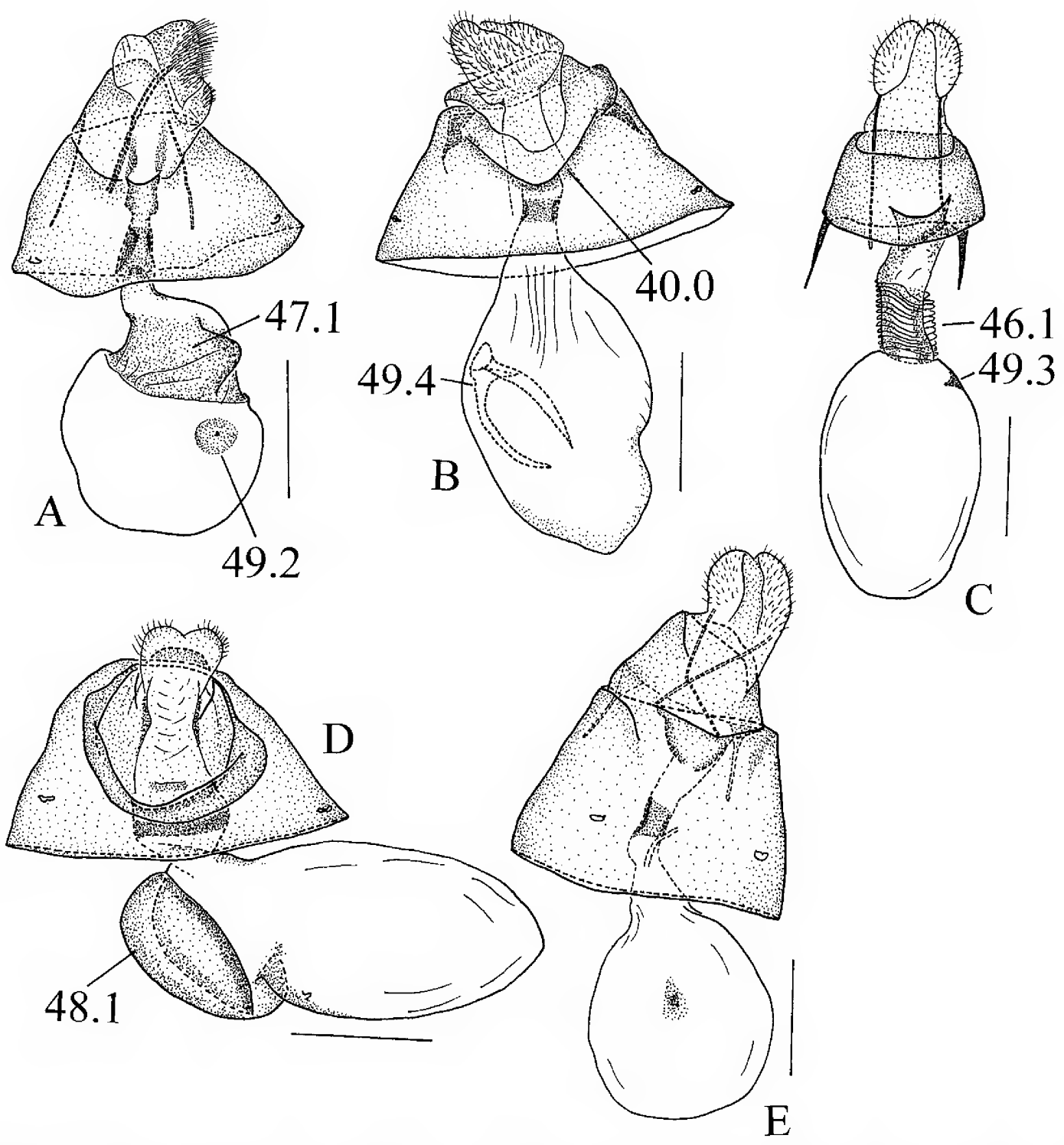

Fig. 15. Female genitalia. Scale bar $=1 \mathrm{~mm}$. A. Eustroma (= Antepirrhoe) semiatratum; B. Evecliptopera illitata; C. Eulithis luteolata; D. E. explanata; E. E. (= Gandaritis) powellata.

sured against the length of the seventh segment. In many the ductus bursae is nearly the same length as the seventh segment. One Eustroma (E. melancholicum) and seven Eulithis (E. testata, E. populata, E. ledereri, E. convergenata, E. gracilineata, E. molliculata, E. mellinata) have a short ductus bursae, but one outgroup (Lampropteryx suffumata) has a very long ductus bursae.

45. Ductus bursae: $(0)$ membranous; (1) sclerotized (fig. 15C). The taxa that have no colliculum (Ceratodalia gueneata, E. luteolata, E. propulsata, E. xylina, E. mellinata) usually show a sclerotized ductus bursae.

46. Wall of ductus bursae: $(0)$ simple; $(1)$ covered by pleated membrane (fig. 15C). The wall of the ductus bursae is usually without modification, but that of two Eulithis (E. luteolata, E. xylina) has pleated membranes.

47. Sclerotization of the opening of corpus bursae: (O) absent; (1) present (fig. 15A). Three Eustroma from North America 


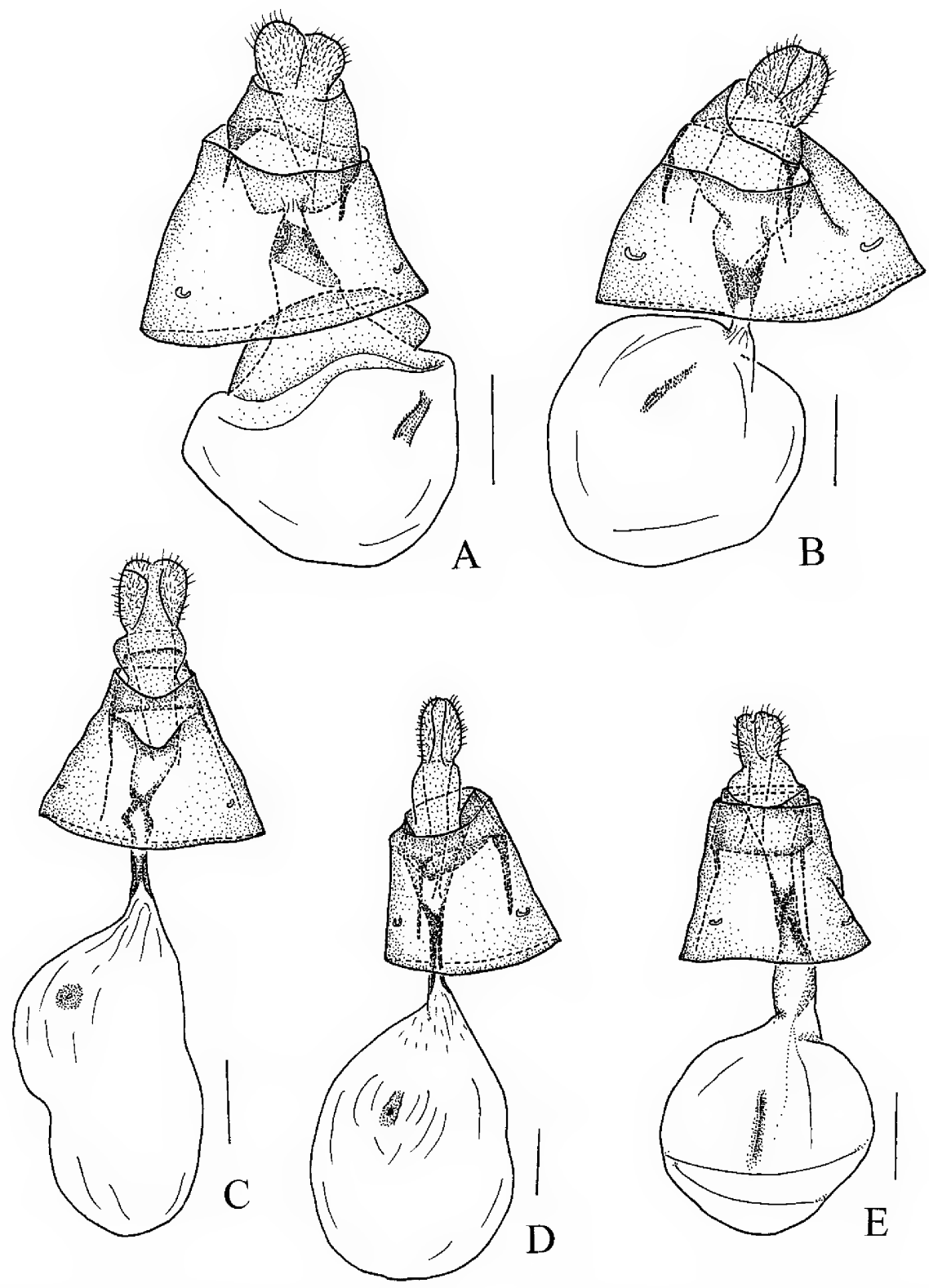

Fig. 16. Female genitalia. Scale bar $=1 \mathrm{~mm}$. A. Chartographa (= Callabraxas $)$ ludovicaria; B. $C$. (= Callabraxas) fabiolaria; C. Callabraxas (= Gandaritis) maculata; D. Gandaritis fixseni; E. Chartographa $(=$ Callabraxas $)$ compositata .

(E. semiatratum, E. fasciatum, E. atrifasciatum) and three Eulithis (E. explanata, E. destinata, and E. mellinata) show a sclerotized opening or bands in the corpus bursae.

48. Appendix bursae in corpus bursae: (0) absent; (1) present. The presence of an appendix bursae is closely related to the pres- ence of a diverticulum on the vesica of the male genitalia, and this feature is interpreted as a lock-and-key mechanism (Mikkola, 1992). For example, the female genitalia of Eulithis explanata have a discoid, sclerotized appendix bursae (fig. 15D) and the male genitalia have a discoid diverticulum (fig. 13G). 
A few members of Callabraxas, Chartographa, Eustroma, and Eulithis show an appendix bursae.

49. Shape of signum: (O) many signa, forming a long, band-shaped patch (fig. 14A); (1) many signa forming a rounded patch (fig. 14B); (2) one dot, surrounded by circular sclerotization (fig. 15A); (3) one single dot without circular sclerotization (fig. 15C); (4) one large, forklike process (fig. 15B); (5) absent. The signum varies from a long, band-shaped patch to a dot and to a large, spikelike process. A long, band-shaped patch of signa is observed in Chartographa and Callabraxas. A rounded patch of signa is observed in Calleulype, Callabraxas, Eucosmabraxas, Eustroma, and Gandaritis. Three Eustroma from North America have a dotlike signum but differ from Cidaria fulvata, Eulithis explanata, and E. luteolata by having the circular sclerotization around the signum. Evecliptopera has a distinct signum, a large, forklike process. Species of Eulithis have four states of signa: long, band-shaped (E. diversilineata, E. molliculata); rounded patch (E. testata, E. populata, E. convergenata, E. pyraliata); one dot (E. explanata, $E$. luteolata, and $E$. destinata); and no signum (E. ledereri, E. xylina, E. mellinata, and $E$. prunata).

50. Signum: $(0)$ separated into two patches (fig. 14C); (1) one patch; (2) absent. Two taxa (Telenomeuta punctimarginaria and Calleulype whitelyi) have two separated patches of signa but the distance between the two signa is different.

\section{Cladistic Analysis}

NONA produced 38 most parsimonious cladograms (length 353, consistency index 0.25 , and retention index 0.57). The strict consensus cladogram is shown in figure 17 . The differences among these original cladograms can be attributed to three genera, Callabraxas, Gandaritis, and Eustroma. Six cladograms show that the genus Eustroma is paraphyletic with Gandaritis, and Callabraxas is a sister group of Eulithis. The other remaining cladograms show that two genera, Gandaritis and Callabraxas, are subgroups of Eulithis, and the genus Eustroma is a monophyletic group. All cladograms support the monophyly of Antepirrhoe.

Successive weighting approach using NONA (with a command "run swt.run hold*hold/30mult*15;") produced one cladogram after two iterations (fig. 18). The cladogram derived from the successive weighting shows fully resolved generic relationships among Callabraxas, Gandaritis, Eustroma, and Eulithis, and is here preferred for the phylogeny of Eulithis and related genera. The cladogram suggests seven monophyletic genera, Evecliptopera, Gandaritis, Eustroma, Callabraxas, Lobogonodes, Eulithis, and a revived genus Antepirrhoe. This includes three new synonyms: Eucosmabraxas and Calleulype of Gandaritis, and Chartographa of Callabraxas.

\section{Character Mapping}

The mapping of five characters from the wing pattern element (characters 9, 13, 14, 15 , and 17) onto the preferred cladogram (fig. 18) produced a couple of different patterns. The first character evolved three times in single individual terminals, Evecliptopera illitata, Chartographa ludovicaria, and Eulithis convergenata. The other four characters evolved twice (figs. 19-23), with slightly different branches of Gandaritis and Callabraxas. Here, the mimetic wing patterns show that they evolved at least twice within the tribe Cidariini: once in the genus Gandaritis and again in Callabraxas.

In the phylogeny of Eulithis and related genera, the line wing pattern evolved five times (fig. 24): (1) Evecliptopera illitata, (2) Eustroma, (3) Chartographa plurilineata + C. ludovicaria + C. compositata, (4) Lobogonodes multistriata, and (5) Eulithis convergenata. This trait is partly overlapped with one of the mimicry patterns (character 9).

\section{DISCUSSION}

The cladistic analysis presented here differs from the classification proposed by earlier authors (table 1). This is presumably due to the addition of new morphological characters including those from both male and female genitalia, and of many more taxa. A sister-group relationship between ingroup 


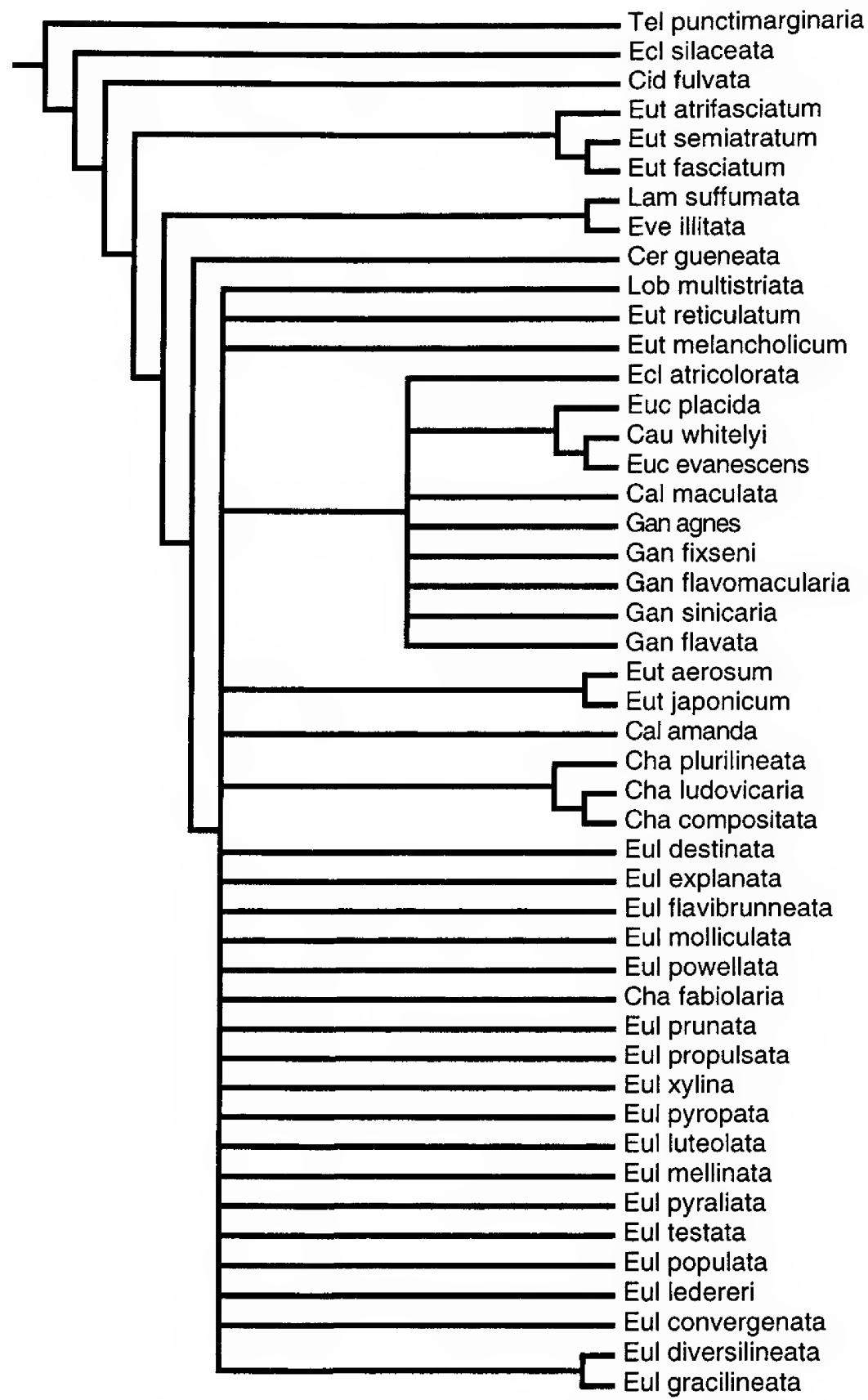

Fig. 17. Strict consensus of 38 equally most parsimonious trees with length of 353 , derived from the data matrix shown in Table 2. Abbreviations for genera, see Table 2.

and outgroup suggests that all groups belong to a monophyletic group, Cidariini, compared to Telenomeuta puntimarginaria. Seven ingroup genera are monophyletically redefined (see Classification, below).

\section{Wing Pattern Evolution}

In the ingroup, the wing pattern of the forewing exhibits one of two basic types. Forewings are usually yellow, brown, or 


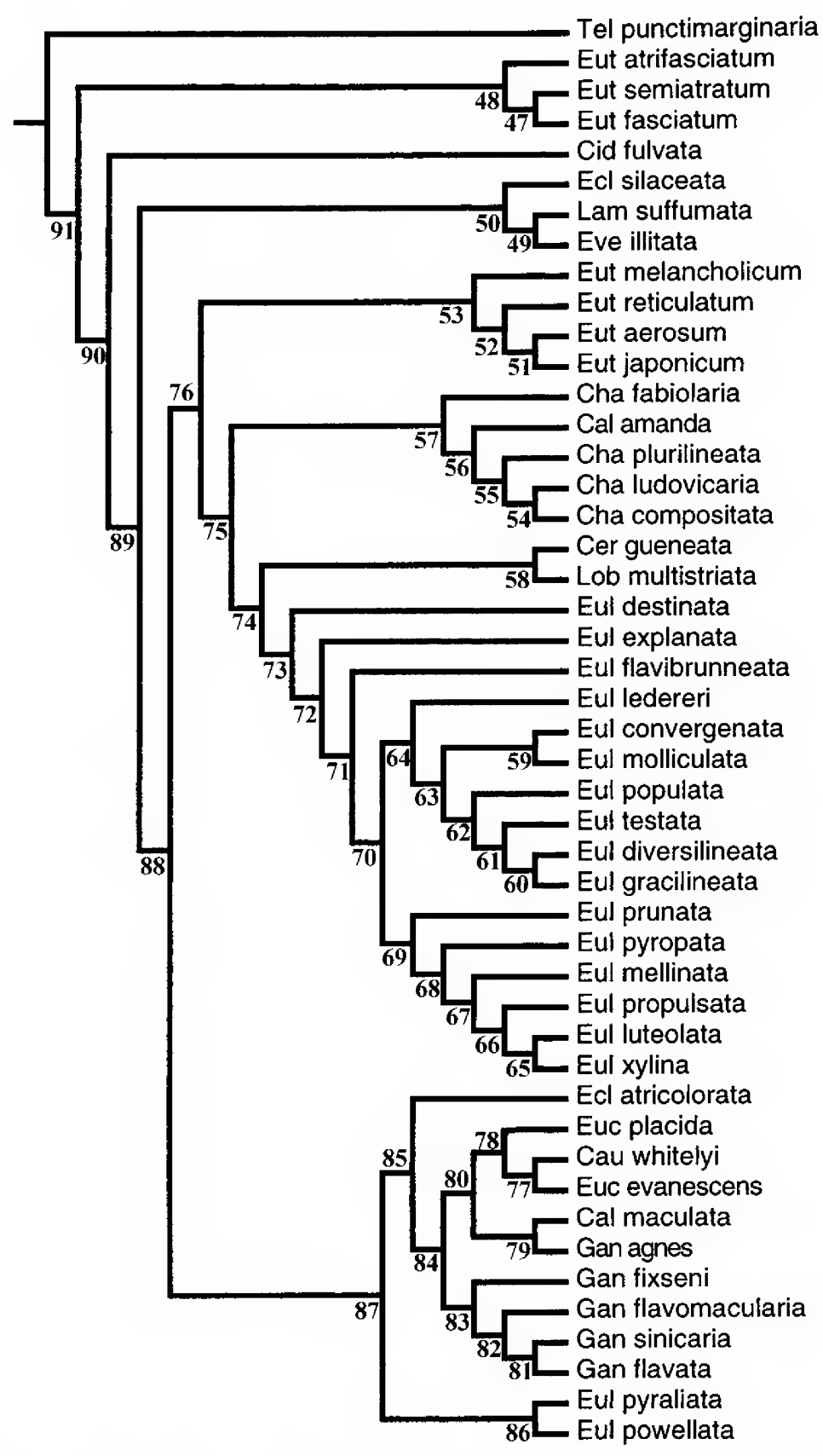

Fig. 18. A cladogram derived from the successive weighting approach. For abbreviations of genera, see table 2 .

blackish with a contrasting band-shaped central fascia consisting of two transverse lines: ante- and postmedial lines (fig. 8A, C) as in Antepirrhoe, Eulithis, Gandaritis. Hindwings are usually paler than forewing, with a black- ish, thin, medial line. This band-shaped fascia is typical in most larentiine moths (Holloway, 1997).

The other type consists of medial lines composed of several oblique lines which con- 


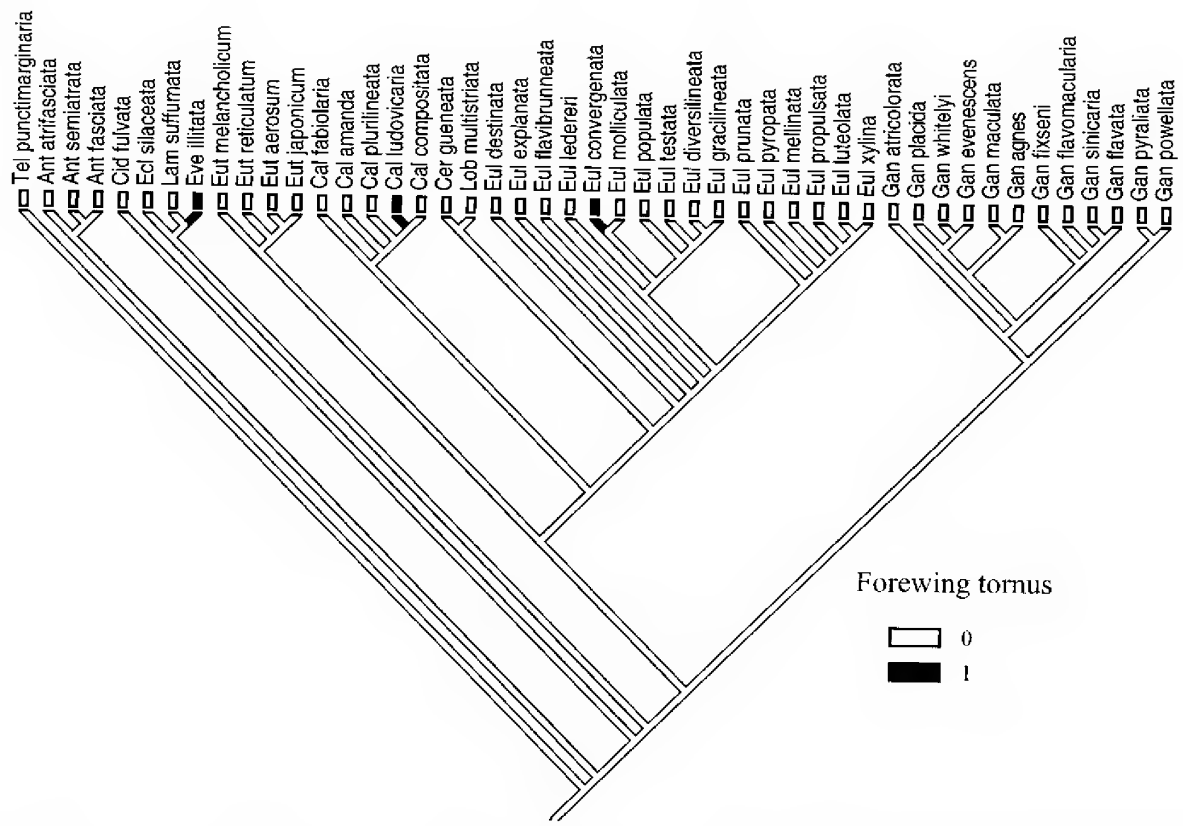

Fig. 19. Character reconstruction over the preferred cladogram of Eulithis and related genera. Presence of yellow marking on the tornus of forewing (character 9). White branches: absent; black branches: present. Genera abbreviations: Tel., Telenomeuta; Ant., Antepirrhoe; Cid., Cidaria; Ecl., Ecliptopera; Lam., Lampropteryx; Eve., Evecliptopera; Eut., Eustroma; Cal., Callabraxas; Cer., Ceratodalia; Lob., Lobogonodes; Eul. Eulithis; Gan., Gandaritis.

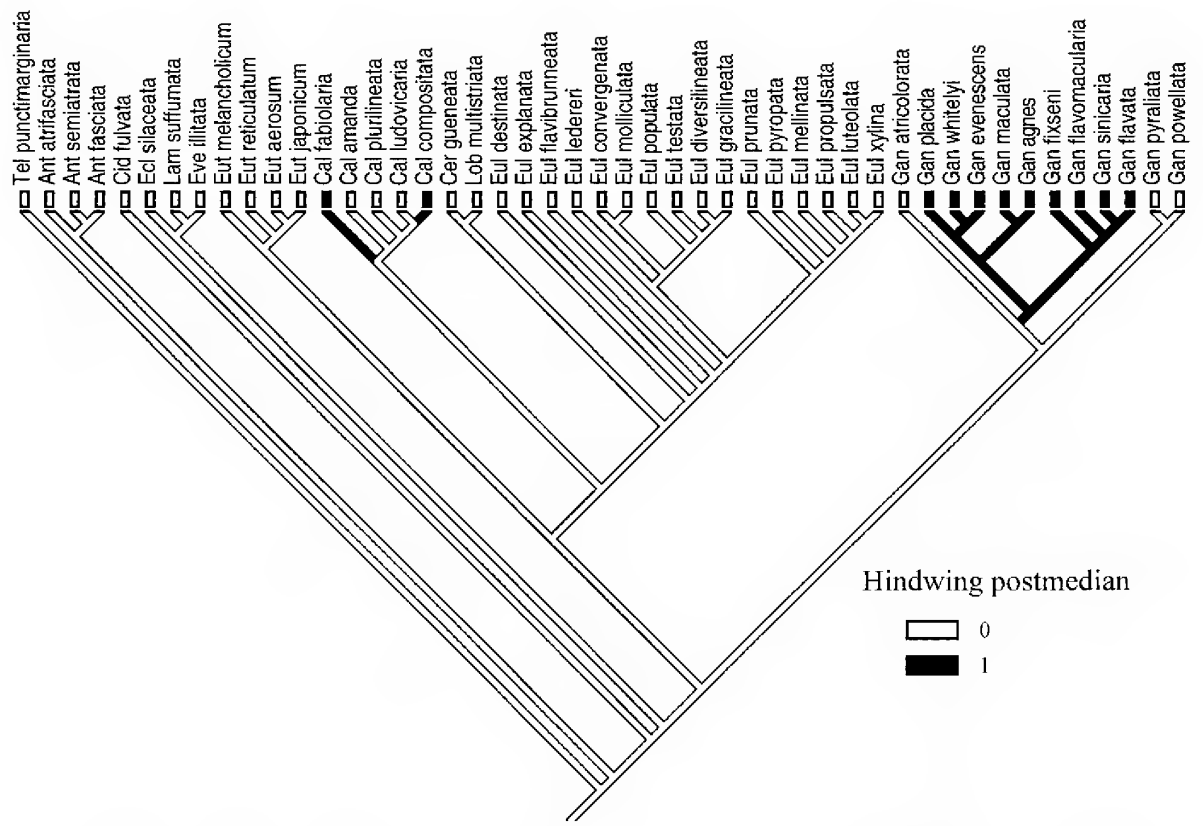

Fig. 20. Character reconstruction over the preferred cladogram of Eulithis and related genera (continued). Distinctive waved marking on the postmedial line of hindwing (character 13). White branches absent; black branches: present. See fig. 19 for abbreviations. 


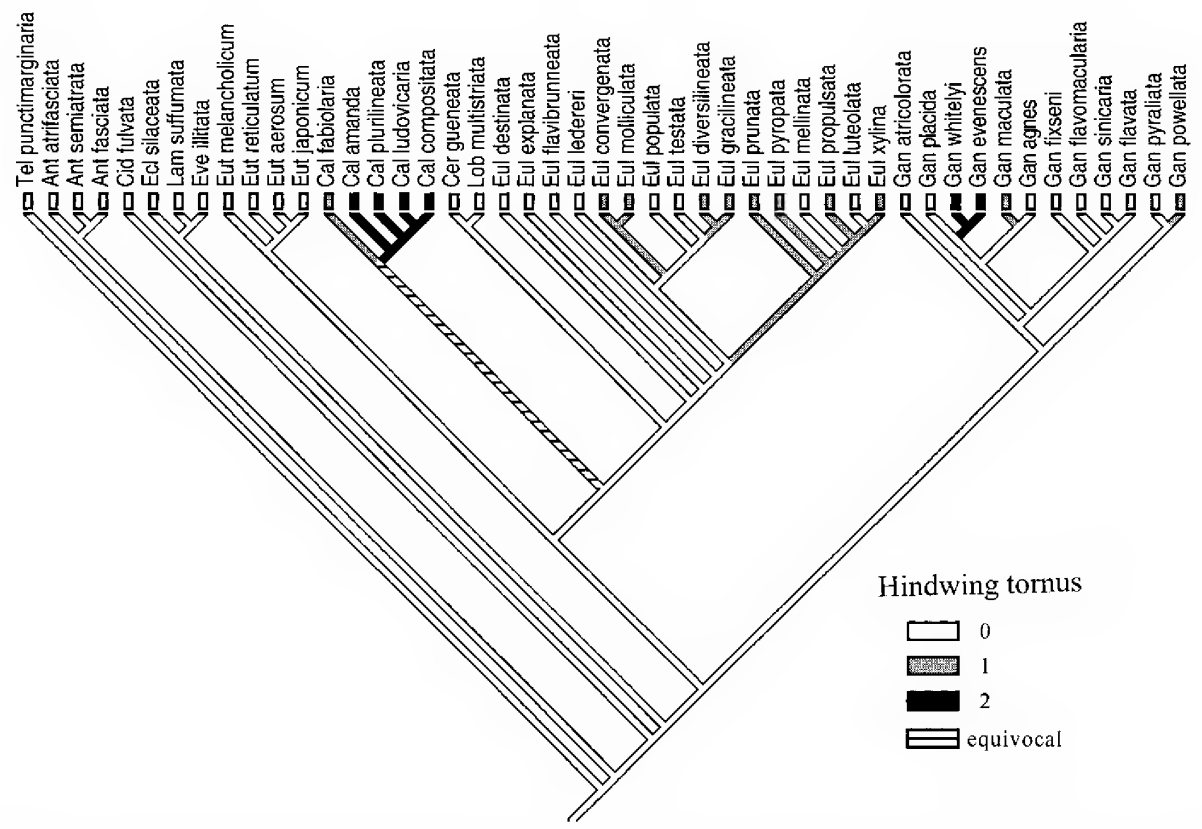

Fig. 21. Character reconstruction over the preferred cladogram of Eulithis and related genera (continued). Presence of marking on the tornus of hindwing (character 14). White branches: without marking; hatched branches: tinged with blackish waved lines; black branches: yellowish marking. See fig. 19 for abbreviations.

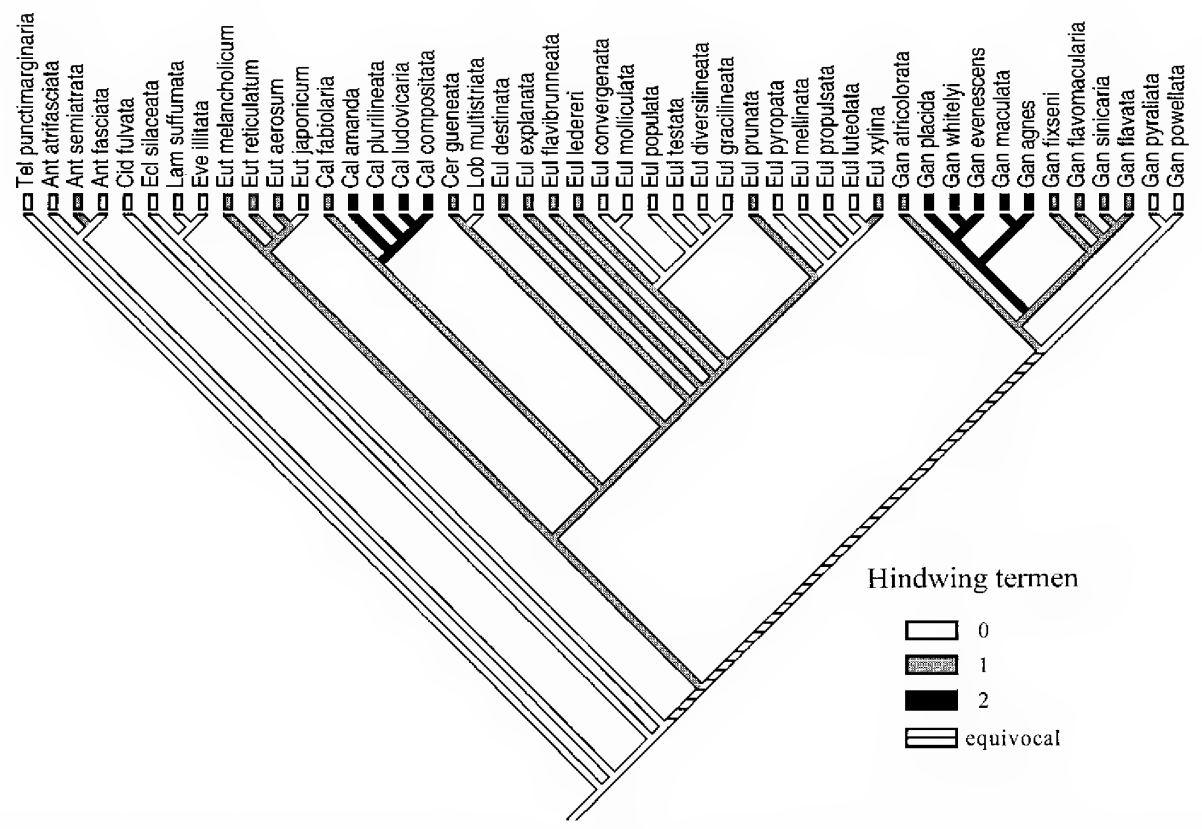

Fig. 22. Character reconstruction over the preferred cladogram of Eulithis and related genera (continued). Shape of termen of hindwing (character 15). White branches: termen same as the rest of wing; dotted branches: presence of waved subterminal lines; black branches: presence of large, black dots; hatched branches: equivocal. See fig. 19 for abbreviations. 


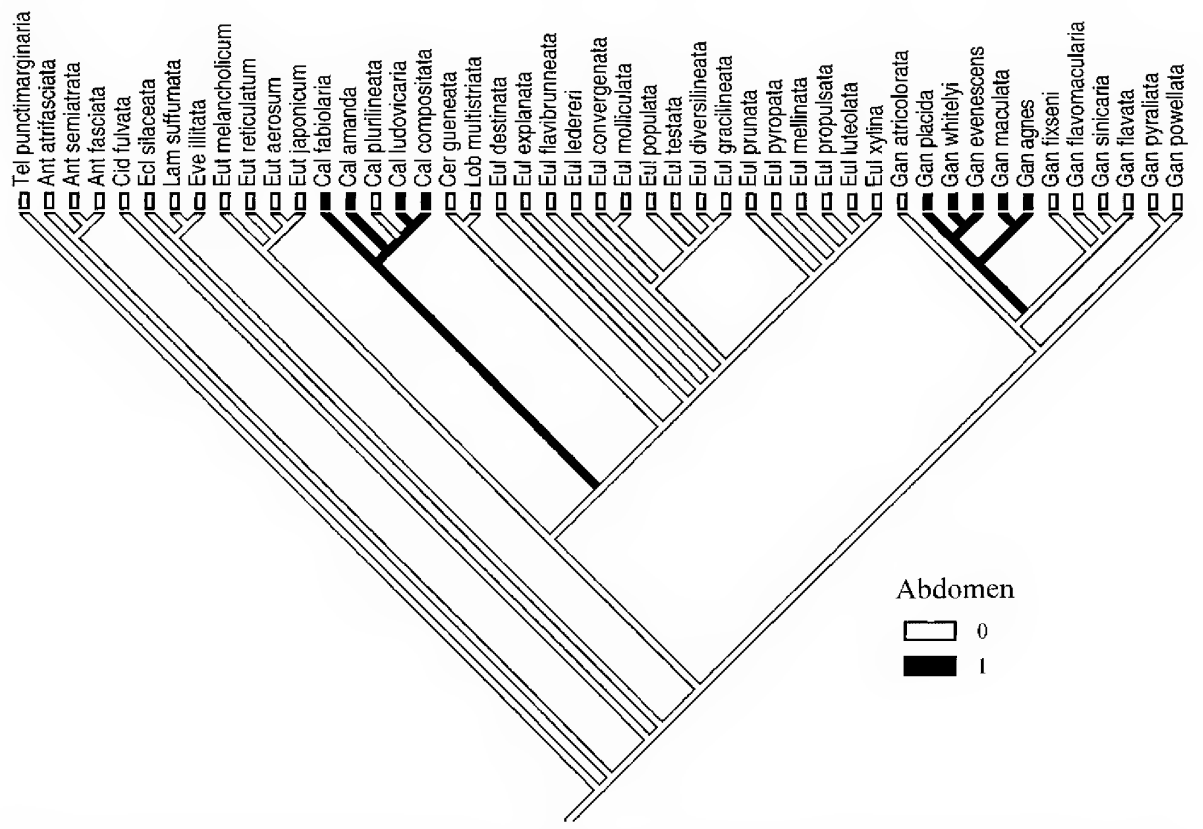

Fig. 23. Character reconstruction over the preferred cladogram of Eulithis and related genera (continued). Presence of black dots on abdomen (character 18). White branches: absent; black branches: present. See fig. 19 for abbreviations.

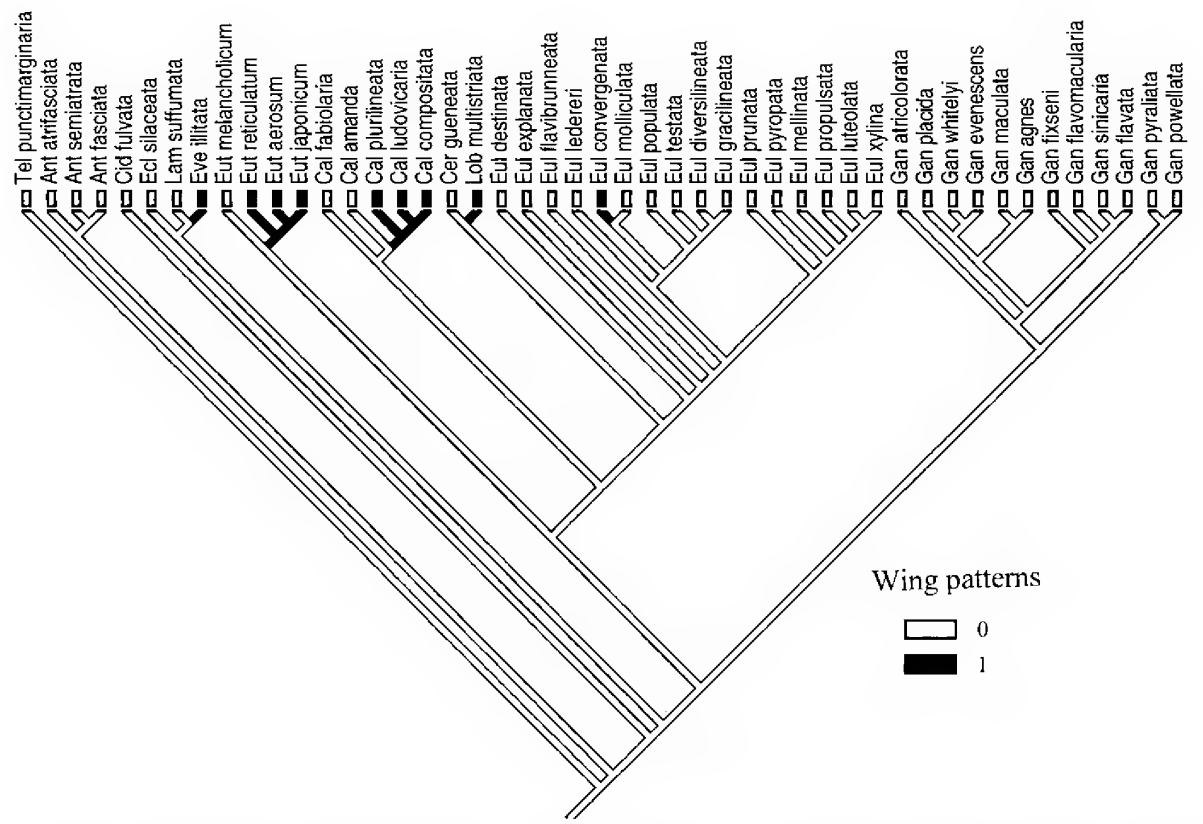

Fig. 24. A reconstruction of wing pattern element. White branches: band-shaped; black branches: lines. 
verge upon the inner margin four-fifths the distance to the tornus (fig. 8B, D). The central fascia of the line pattern type is indistinct except in Lobogonodes. Hindwing is frequently the same color as the forewing, but with a medial line. The medial line is often distinguished by a thick, wavy, blackish medial line (e.g., Gandaritis; fig. 8C) and the termen has yellowish markings with large black dots (e.g., Callabraxas; fig. 8B). This line type is rare in larentiines, but often occurs in the Oriental and Neotropical Ennominae: Ourapteryx Leach, Phrygionis Hübner, Pityeja HerrichSchäffer, and Opisthoxia Hübner.

Here, the line-patterned element has evolved five times. However, these five clades are different in the wing ground color and the composition of the medial lines (fig. 8B, D). The three clades, Evecliptopera, Lobogonodes, and Eustroma, have a blackish wing color, and the other two clades (Eulithis convergenata and Callabraxas plurilineata $+C$. ludovicaria $+C$. compositata) have white wings. In Eustroma, Evecliptopera, and Lobogonodes, the medial lines run separately (fig. 8D), but in the other two clades, two groups of lines, each consisting of three parallel lines, run toward the inner margin (fig. $8 \mathrm{~B})$. This reveals that wing pattern evolution within the Cidariini is more complicated than it first appears.

Five characters for tracing mimicry are included in the present analysis: yellow marking at the tornus of the forewing (character 9; see fig. 19), distinctive marking on the postmedian (character 13; see fig. 20) and tornus of the hindwing (character 14; see fig. 21), termen of hindwing with black dots (character 15; see fig. 22), and abdomen with black dots on white or yellow ground color (character 17; see fig. 23). Overlaying these characters onto the cladogram suggests that this mimicry pattern evolved at least twice within the ingroup: once in clade 82 (a subclade of Gandaritis) and again in clade 56 (a subclade of Callabraxas). A yellowish marking on the tornus of the forewing has evolved three times independently: in Evecliptopera illitata, Eulithis convergenata, and Callabraxas ludovicaria. This result can be summarized that mimicry patterns have evolved at least twice within the Cidariini.

The character mapping above reveals an example of convergent evolution in several larentiine species in which distributions of line wing pattern and mimicry pattern are overlapped. The mimetic pattern evolves rapidly by runaway processes (Mallet and Singer, 1987). Miller (1996), in his analysis of the Josiini, supported the rapid evolution of wing patterns within the tribe. He postulated that a rare phenotype, longitudinal wing stripes, appears at least twice in the evolution of Josiini.

The species pair Callabraxas ludovicaria and C. compositata (fig. 1) is an example of the maintenance of signal in the mimicry complex. These two species are nearly indistinguishable by wing pattern and genitalia; $C$. compositata can be identified by the blackish medial line and termen of the hindwing. However, the other morphological structures of $C$. compositata are different from those of C. ludovicaria: very short labial palps, rounded frons, one areole in the forewing (although variable in the species), the presence of a process at the base of the anellus lobe, and the antrum (fig. 16). The present study suggests that the similar wing patterns occur due to common ancestry, the conclusion being that although several morphological differences have evolved, the mimicry pattern has been maintained as a signal.

The cause of this mimicry complex is uncertain. However, it is presumably generated by distasteful species of the ennomine genus Abraxas. The toxicity of Abraxas glossulariata is known (Prout, 1915; Ford, 1955) as an unpleasant, bitter flavor in all life stages, even to insectivorous birds. However, the biology of those larentiine genera is scarcely known, and whether they form Batesian or Mullerian mimicry complexes is open to speculation. As Joron and Mallet (1998) have noted, one of the major barriers to understanding mimicry is the lack of detailed field investigations. Thus, future work should include field studies in order to provide a better understanding of the nature of this apparent mimicry.

\section{CLASSIFICATION}

\section{KEY TO THE GENERA}

1. Wings white, yellow or ochreous; termen of hindwing distinct with orange band with blackish dots .............. 2 
- Wings brownish or yellowish white; termen of hindwing indistinct .......... 3

2. Central fascia of forewing consists of blackish dots or band and projected outwardly at the subcosta; postmedial line of hindwing distinct with thick, waved band ..... ...Gandaritis (figs. 1: 2nd and 3rd rows, figs $2 \mathrm{~A}, 3 \mathrm{H}, \mathrm{J})$

- Central fascia incomplete by ochreous band broken at the costa or oblique medial lines converged upon the tornus; postmedial line indistinct

...Callabraxas (fig. 1: 4th and 5th rows)

3. Central fascia of forewing band-shaped, formed by ante- and postmedial lines . . 4

- Central fascia consists of lines, running from costa to inner margin ...........5

4. Frons variable from yellowish unicolorous scales to mixed scales; labial palp long, more than twice the eye diameter; sexual tufts present and fan-shaped ........

........ Eulithis (figs. 2I, J, 3A-G, I)

- Frons with appressed scales or with marginally different scales; labial palp moderate, about 1.5 times eye diameter; sexual tufts present or often absent, consisting of thin, black, long hairs

........... Antepirrhoe (figs. 2C, D)

5. Medial lines occur on both fore and hindwings; antemedial lines run transversely from costa to inner margin; a triangular discoidal dot present; frons with white, unicolorous scales ............... $\ldots \ldots \ldots$. . . . . Lobogonodes (fig. 2B) medial lines run obliquely; discoidal dot absent; frons V-shaped, with white scales on the edge .............. 6

6. Tornus of forewing distinct, with yellowish marking; sexual tufts on the underside of male forewing absent; sexual dimorphism on the hindwing absent ..........

$\ldots \ldots \ldots \ldots$ Evecliptopera (fig. 2E)

- Tornus of forewing indistinct; sexual tufts present; sexual dimorphism on the hindwing present $\ldots \ldots \ldots \ldots \ldots \ldots$

$\ldots \ldots \ldots$ Eustroma (figs. $2 \mathrm{G}, \mathrm{H}, 3 \mathrm{H}, \mathrm{J}$ )

\section{TAXONOMY}

Antepirrhoe Warren, revised genus Figures 2C, D, 10C, 13A, 15A

Antepirrhoe Warren, 1905, Novit. Zool. 12: 327. Type species: Cleora atrifasciata Hulst, 1888, Entomologica Am. 3: 214, by original designation.

DiAgnosis: Three species of Antepirrhoe have filiform antennae; with moderate labial palps, being about 1.5 times eye diameter; frons with marginally different scales or appressed scales; forelegs with distinct tibial joints; and male forewing underside with brown sexual tufts, missing in A. atrifasciata. Wings are dark brown or white; forewing with blackish central fascia; hindwing with medially projected, blackish medial line (figs. 2C, D). Members of Antepirrhoe are similar to Eulithis destinata in the shape of the central fascia, but differ in the male genitalia in the dome-shaped tegumen, the sclerotized and medially expanded costa with a distal process, and the large, spinular cornuti in the vesica (figs. 10C, 13A). Female genitalia of Antepirrhoe (fig. 15A) consist of a simple, membranous ostium; moderate, membranous ductus bursae with a colliculum; corpus bursae with sclerotized appendix bursae or sclerotized lines present at the opening; and one dotlike signum present in the corpus bursae.

BIOLOGY: Adults fly from July to September in New York (Forbes, 1948) and from April to October in British Columbia (Jones, 1951). Larvae of A. semiatrata feed on Epilobium (Onagraceae) (Dyar, 1904).

Distribution: Three species of Antepirrhoe are known exclusively from North America. A. fasciata and A. atrifasciata occur along the northwest coast of North America, extending southward to California. $A$. semiatrata is widely distributed from Alaska southward into Nevada and also eastward to the northeast coast of Canada and the United States.

Discussion: Warren (1905) described the genus Antepirrhoe based on the shape of the discocellular cell in the hindwing. He included three additional species; two from northern India and one from Bolivia. I have not had the opportunity to study these taxa [ $\mathrm{va}$ cillans Warren, 1905; homophana (Hampson, 1895); latifusata (Walker, 1862)] in this study. One species, Eustroma lativittaria Moore from northern India, is similar in wing pattern but the male and female genitalia of this species are quite different from Antepirrhoe. Thus, the inclusion of this species into Antepirrhoe is unlikely.

The genus Antepirrhoe is placed in the very basal clade (figs. 17, 18) and is mono- 
phyletic, being supported by seven synapomorphies: spinular hairs present on the hole of the juxta, the distally wider valva, the costa medially expanded and sclerotized, valva distal with vertical end, the ostium bursae with stripes, the presence of an appendix bursae, and the dotlike signum. Since Grossbeck (1907), who first noted that the habitus of $A$. atrifasciata is close to Eustroma, three species of Antepirrhoe have been placed under Eustroma (e.g., McDunnough, 1943; Ferguson, 1983). Both Antepirrhoe and Eustroma have moderate-length labial palps, the frons with V-shaped marginal scales, the male sexual tufts on the underside of the forewing originating between anal vein and inner margin, the moderate length of the anellus lobe, with hairs on the apical part and arm, and the simple, membranous ostium and ductus bursae. Antepirrhoe differs, however, in the shape of the central fascia of the forewing, the shape of the male eighth sternite, the dome-shaped tegumen, the expanded anellus lobe, the presence of a hole on the juxta, the sclerotized costa with a distal process of the valva, the spinular cornuti on the vesica, and the sclerotized corpus bursae with a signum. Based on the shape of the vesica and the corpus bursae, Antepirrhoe appears close to Dysstroma.

\section{SPECIES INCLUDED:}

atrifasciata (Hulst, 1888)

semiatrata (Hulst, 1881)

fasciata (Barnes and McDunnough, 1918)

\section{Evecliptopera Inoue Figures 10B, 15B}

Evecliptopera Inoue, 1982, Moths of Japan 1: 484. Type species: Cidaria decurrens Moore, 1888, Descr. New Indian Lepid. Insects Coll. late Mr. W.S. Atkinson (3): 276, by original designation.

DiAGNOSIS: Species of Evecliptopera are distinguished by long labial palps, the absence of sexual tufts on underside of male forewing, and the wings' blackish ground color, with many oblique lines. Members of the genus are similar to Eustroma in the wing pattern, but differ in the absence of sexual tufts, the yellowish marking at the termen of forewing, and the presence of coremata on the male eighth sternite. The male genitalia of Evecliptopera (fig. 10B) are distinguished by the long, triangular tegumen, the shallow saccus, V-shaped connection between anellus lobe and juxta, the expanded apical part of an anellus lobe, the slender, membranous valva, and two small groups of spinular cornuti on the vesica. The female genitalia (fig. 15B) are distinguished by the large, fork-shaped signum of the corpus bursae.

Biology: Members of the genus are bivoltine. In northern India $E$. decurrens was collected from December to February and from June to July; E. illitata from Japan and Korea in May and August. In Japan E. illitata occurs on Akebia (Lardizabalaceae) (Sato and Nakajima, 1987).

DistRIBUTION: Members of the genus are known from northern India, Nepal, southwestern China (decurrens), Taiwan and the Far East countries (illitata).

Discussion: In the present analysis, one species of Evecliptopera has seven autapomorphies: long labial palp; frons with mixed scales; dorsum of thorax and abdomen indistinct without white, parallel lines; yellow marking on the tornus of the forewing; wing pattern consisting of lines; membranous subscaphium; and two patches of cornuti. This genus seems to be monophyletic. Species of Evecliptopera are similar to Eustroma and Lobogonodes, but have distinctive wing markings on the tornus of the forewing, wing patterns, and male and female genitalia. One taxon, E. illitata, is upgraded to full species status. The original description (Wileman, 1911) was based on a single male specimen showing strikingly different wing pattern from the typical species of Evecliptopera. Inoue (1982) placed this taxon as a subspecies of $E$. decurrens. Genitalic examination of the holotype in the BMNH (genitalia slide number 19899) confirms that this species is an Evecliptopera, distinct from $E$. decurrens.

\section{Species InCluded:}

decurrens (Moore, 1888)

illitata (Wileman, 1911) REVISED STATUS

$=$ excurrens (Prout, 1930) NEW SYNONYMY

$=$ insurgens (Prout, 1930) NEW SYNONYMY

ssp. acreta (Prout, 1940) 


\section{Gandaritis Moore}

Figures 1, 10A, 11A, B, 12B, C, 13D, F, 14C, D, 16C, D

Gandaritis Moore, 1868, Proc. Zool. Soc. London 1867: 660. Type species: Gandaritis flavata Moore, 1868, Proc. Zool. Soc. London 1867: 660 , by monotypy.

Calleulype Warren, 1903, Novit. Zool. 10: 264. Type species: Abraxas whitelyi Butler, 1878, Illust. Typical Specimens Lepid. Heterocera Coll. Br. Mus. 2: 52, pl. 37, fig. 4, by original designation. NEW SYNONYMY

Eucosmabraxas Prout, 1937, Gross-Schmett. 4 (Suppl.): 107. Type species: Abraxas placida Butler, 1878, Ann. Mag. nat. Hist. (5)1: 441, by original designation. NEW SYNONYMY

DIAGNOSIS: Wings are white (whitelyi, maculata, placida, agnes), yellow (fixseni, flavata, sinicaria), or orange (octoscripta, intersectaria, flavomacularia) (fig. 1). The central fascia of the forewing, comprising dots or a band, is strongly projected outwardly on the middle of veins $\mathrm{M}_{2}$ or $\mathrm{M}_{3}$. Termen of both fore- and hindwings usually shows an orange band with blackish dots. Male genitalia (figs. 10A, 11 A, B, 12B, C, 13D, F) are similar to Eulithis, but distinguished by the long anellus lobe that exceeds the half length of tegumen, the broad apical part of the anellus lobe with long, dense hairs, the medially slightly expanded costa of the valva, and the lack of cornuti in the vesica. Female genitalia (figs. 14C, D, 16C, D) are indistinguishable from Callabraxas, except by larger size, and the signa.

BIOLOGY: In Europe, G. pyraliata feeds on Galium (Rubiaceae) (Skinner, 1984). In Japan, several species of Gandaritis feed on Actinidia (Actinidiaceae) (whitelyi, fixseni, agnes). G. placida, and G. evanescens feed on Hydrangea and Schizophragma (Saxifragaceae) (Sato and Nakajima, 1987).

Distribution: The genus is Holarctic. Most species are known from East Asia, except G. pyraliata (Europe), and G. powellata and $G$. atricolorata (North America). $G$. powellata is only known from California, whereas $G$. atricolorata occurs along the East coast, from Quebec to Georgia and west to Missouri (Forbes, 1948).

DisCUSSION: Inoue (1944) compared the species of Gandaritis with Lygris (a junior synonym of Eulithis) and separated them by the shape of the valva and cornuti. In the present analysis, many cladograms derived from an equal weighting supported the grouping of Gandaritis and Eulithis. Although my preferred cladogram derived from successive weighting (fig. 18) supported the monophyly of Gandaritis sensu stricto (node 83 ), the concept of this genus is now broadly redefined, comprising species from western Palearctic and Nearctic (nodes 80 and 86). Two synapomorphies are present: the narrowed basal part of the anellus lobe, and the absence of cornuti. Hampson (1895) included the following species of Gandaritis ( $i$ xseni, pyraliata, flavata, and agnes) based on the absence of sexual characters of the forewing. Here, a striking placement is Gandaritis atricolorata. Since Forbes (1948) placed this species in Diactinia Warren $(=$ a junior synonym of Ecliptopera) based on wing pattern, the status of this species has never been questioned. However, careful examination of the morphology, including male and female genitalia, suggests that this species belongs to Gandaritis, not Ecliptopera.

\section{SPECIES INCLUDED:}

agnes (Butler, 1878)

atricolorata (Grote and Robinson, 1866) NEW COMBINATION

evanescens (Butler, 1881) NEW COMBINATION

= borearia (Inoue, 1958) NEW SYNONYMY

fixseni (Bremer, 1864)

flavata Moore, 1868

ssp. postscripta (Prout, 1941)

flavescens Xue, 1992

flavomacularia Leech, 1897

impleta (Xue, 1990) NEW COMBINATION

maculata (Swinhoe, 1894) NEW COMBINATION octoscripta (Wileman, 1912) NEW COMBINATION powellata (Ferguson and Choi) NEW COMBINATION placida (Butler, 1878) NEW COMBINATION

= propinqua (Butler, 1881) NEW SYNONYMY postalba Wileman, 1920

pseudolargetaui (Wehrli, 1933) NEW COMBINATION pyraliata ([Denis and Schiffermüller], 1775) NEW

COMBINATION

sinicaria Leech, 1897

subalba (Prout, 1941)

tricedista (Prout, 1938)

tristis (Sterneck, 1928)

whitelyi (Butler, 1878) NEW COMBINATION

ssp. leechi (Inoue, 1955) NEW COMBINATION 


\section{Eustroma Hübner}

Figures 8A, D, 10D, 13C, 14A

Eustroma Hübner, 1816, Verz. Bekannter Schmett.: 335. Type species: Geometra reticulata [Denis and Schiffermüller], 1775, Ankündung syst. Werkes Schmett. Wienergegend: 114 , by subsequent designation (Warren, 1893, Proc. Zool. Soc. London 1893: 335).

DiAgnOSIS: Members of the genus have filiform antennae in both sexes, but bipectinate male antennae in several species (e.g., $E$. elistum, E. promachum). Sexual tufts are present on the underside of male forewing. Forewing is brownish, with white or yellowish transverse lines toward the termen; anteand postmedial lines form a central fascia, but the size of fascia is variable. Hindwing is lighter in color than forewing, often orange (e.g., E. aurantiarium); and termen with waved medial and subterminal lines. The male genitalia (figs. 10D, 13C) are similar to Eulithis, but differ in the juxta-anellus lobe complex and the less developed cornutus on the vesica. The female genitalia (fig. 14A) are distinguished by having a funnel-shaped antrum, a moderate, membranous ductus bursae with a colliculum, and long, patchlike signa of the corpus bursae.

BIOLOGY: Larvae of E. reticulatum feed on Impatiens (Balsaminaceae) in England (Skinner, 1984). Sato and Nakajima (1987) noted that E. melancholicum was reared on Vitis (Vitaceae).

DISTRIBUTION: The genus Eustroma is northern Oriental and Palearctic in distribution. Many species occur exclusively in the Oriental region: northern India, southwestern China, and Taiwan (aurantiarium, aurigenum, elistum, chalcopterum, hampsoni, promachum, changi). E. melancholicum occurs from northern India to Japan, and E. reticulatum occurs in all parts of the Palearctic, from Europe to the Far East.

Discussion: The monophyly of Eustroma is supported (fig. 18, node 53) by several synapomorphies: frons with distinct marginal scales, dorsa of head, thorax, and abdomen with parallel white lines, foreleg tibial joints distinct, with white scales, distal end of valva vertical, and the signum arranged in a minute circle. Species relationships of Eustroma are well resolved. E. aerosum and E. japonicum form the sister group of E. melancholicum. These three species are known from Asia. $E$. reticulatum occurs widely throughout the Old World and is similar to E. aerosum in the forewing patterns and the presence of a sexual marking in the fore- and hindwing. This species differs from E. aerosum in characters of the male genitalia, particularly the vesica.

Members of Eustroma can be divided into three subgroups based on the wing patterns: reticulatum group, melancholicum group, and elistum group. The first two groups are similar in the male and female genitalia, and the third group is distinguished by the large anellus lobe of the male genitalia. The wing pattern of each group shows resemblances with the relatives: the reticulatum group with Evecliptopera; the elistum group with Lobogonodes; and the melancholicum group with Ecliptopera. This suggests that each wing pattern has also evolved independently within the Cidariini. Two species of reticulatum group, aerosum and japonicum, have spines on the juxta, a feature that also occurs in Hysterura Warren. The present cladistic study using four species has revealed two limitations: the basal clade supported by homoplasious characters, and taxon sampling. Due to the recognition of three species-groups in Eustroma, future phylogenetic studies will be needed to test the monophyly and recover more detailed relationships among the species.

\section{SPECIES INCLUdED (* indicates unexamined} taxon):

reticulatum group aerosum (Butler, 1878)

changi Inoue, 1986

hampsoni Prout, 1958

inextricatum (Walker, 1866)

japonicum Inoue, 1986

mixtilineatum (Hampson, 1895) NEW COMBINATION reticulatum ([Denis and Schiffermüller], 1775)

ssp. dictyotum (Prout, 1937)

*ssp. obsoletum Diakonoff, 1929

elistum group

aurigenum (Butler, 1880)

chalcopterum (Hampson, 1895)

elistum Prout, 1940

melancholicum group

aurantiarium (Moore, 1868) 
melancholicum (Butler, 1878)

$=$ venulatum (Oberthür, 1880) NEW SYNONYMY

ssp. venipictum Warren, 1893

ssp. brunnearium Leech, 1897

= interruptum (Wileman, 1911) NEW SYNONYMY

promachum Prout, 1940

Ambiguous

*mardinatum Staudinger, 1895 (Lygris)

\section{Callabraxas Butler}

Figures 8B, 11C, D, E, 13E, 16A, B, C, E

Callabraxas Butler, 1880, Ann. Mag. Nat. Hist.

(5) 6: 226. Type species: Callabraxas amanda

Butler, 1880, Ann. Mag. Nat. Hist. (5) 6: 226, by original designation.

Chartographa Gumppenberg, 1887, Nova Acta Acad. Caeser. Leop. Carol. 49: 325 (key). Type species: Cidaria ludovicaria Oberthür, 1879, Diagnoses Espéces nouv. Lépid. ile Askold: 10, by subsequent designation (Prout, 1914: 210). NEW SYNONYMY

Callygris Thierry-Mieg, 1904, Naturaliste 18: 141. Type species: Abraxas compositata Guenée, 1857, in Boisduval and Guenée, Hist. Nat. Insectes (Spec. gén. Lépid.) 10: 207, by subsequent designation (Fletcher, 1979: 34). [A junior synonym of Chartographa Gumppenberg, see Xue and Zhu, 1999]

DiAGNOSIS: Species of a newly defined genus Callabraxas are characterized by the mimetic wing patterns: forewings of white ground color with distinctive blackish markings; hindwings whitish with an orange band and blackish dots on the termen. The central fascia of forewing is ochreous or dark red band (amanda, trigoniplaga, fabiolaria) or brownish lines, converging on the tornus (plurilineata, ludovicaria, compositata) (fig. 1). Male genitalia (figs. 11C, D, E, 13E) are similar to those of Eulithis, but distinguished by the dentate transtilla (fabiolaria, trigoniplaga) and the androconial hairs on the valva (amanda). Female genitalia (figs. 16A, B, C, E) are distinguished by the wide, funnelshaped ostium (fabiolaria, ludovicaria).

BIOLOGY: Sato and Nakajima (1987) recorded that C. compositata feeds on Parthenocissus (Vitaceae).

DISTRIBUTION: All species are known from Asia.

Discussion: Prout (1914) listed Chartographa under Lygris based on the following morphological features: palpus with third joint concealed; wings broad, distal margins smooth, that of hindwing ventricose; male hair-tuft normal. He noted that this genus shows structural transition between Lygris and Callygris Thierry-Mieg. In the present analysis, the basal clade of Callabraxas and Chartographa is weakly supported by one character: distinguishing blackish dots on abdomen. Neither Callabraxas nor Chartographa is found to be monophyletic, Callabraxas maculata being a sister species of Gandaritis agnes; Chartographa fabiolaria being a sister species of Callabraxas amanda (fig. 18). Here I synonymize the genus Chartographa with Callabraxas.

\section{SPECIES INCLUdED:}

amanda Butler, 1880

compositata (Guenée, 1858) NEW COMBINATION ssp. apothetica (Prout, 1940) NEW COMBINATION ssp. basistrigaria (Wileman, 1912) NEW COMBINATION

convexa (Wileman, 1912) NEW COMBINATION fabiolaria (Oberthür, 1884) REVISED COMBINATION ssp. candida (Inoue, 1989) NEW COMBINATION intersectaria (Leech, 1897) NEW COMBINATION liva (Xue, 1990) NEW COMBINATION ludovicaria (Oberthür, 1879) NEW COMBINATION = tertrivia (Prout, 1937) NEW SYNONYMY = praemutans (Prout, 1937) NEW SYNONYMY nigritella (Xue, 1992) NEW COMBINATION plurilineata (Walker, 1862) NEW COMBINATION trigoniplaga (Hampson, 1895) NEW COMBINATION

\section{Lobogonodes Bastelberger}

Figures 2B, 12A

Lobogonodes Bastelberger, 1909, Dt. Entomol. Z. Iris 22: 168. Type species: Hypenorhynchus permarmorata Bastelberger, 1909, Entomol. Z. Frankf. M. 23: 34, by original designation.

Microlygris Prout, 1914, Gross-Schmett. 4: 207. Type species: Cidaria multistriata Butler, 1889, Illust. typical specimens in Lepid. Heterocera Coll. Br. Mus. 7: 24, 119, pl. 137, fig. 21, by original designation. NEW SYNONYMY

Diagnosis: Species of Lobogonodes are distinguished by the long labial palp, the brownish wings with many transverse lines in both fore- and hindwings, the medially projected transverse lines, and the distinct discoidal dot and black, triangular marking between antemedial and postmedial lines (fig. 2B). They are similar to Eustroma in wing pattern, but differ in the direction of 
transverse lines toward the inner margin, the pattern of the hindwing, and the presence of a saccus process in the male genitalia. The male genitalia (fig. 12A) are distinguished by the bilobed apical part of the anellus lobe, the U-shaped connection between anellus lobe and juxta, the medially strongly projected saccus with a large process, the distally wider valva, and the membranous vesica without cornutus. Female genitalia are variable within the genus (based on $L$. multistriata and $L$. permarmorata): antrum straight or funnel-shaped; colliculum present; length of ductus bursae moderate to very long, twice the length of seventh segment; and signum in corpus bursae comprising small dots arranged in a circle with one large dot, or one dot.

BIOLOGY: Sato and Nakajima (1987) noted that $L$. erectaria feeds on Hydrangea (Saxifragaceae) and L. complicata on Parthenocissus (Vitaceae).

Distribution: Members of the genus are Asian. Two species are known from northern India (porphyriata, multistriata) and three species are from Taiwan (permarmorata, taiwana, complicata). Three species, multistriata, erectaria, and complicata, occur in Korea, Japan, and south Primorye.

DisCUSSION: The apomorphic characters of L. multistriata in the present study are the frons with uniform scales, the dorsa of head, thorax and abdomen with distinct parallel, white lines, the foreleg without distinct joints, the wing pattern with lines, the termen of the hindwing same as the rest of the wing, the large saccus process, the short anellus lobe hairs, and the absence of a cornutus. Prout (1937-38) divided the genus Lobogonodes into two groups, Microlygris Prout and Lobogonodes, based on the presence of hair pencils under the male forewing and the state of vein $M_{1}$. Since Prout, these two subgroups have been treated as separate genera (e.g., Inoue, 1992; Xue and Zhu, 1999). The character, presence of hair pencils, is a good diagnostic character at the species level, but is often inconsistent in the generic level (e.g., Antepirrhoe). Thus, grouping based on this character is unreliable.

The morphological characters of Lobogonodes permarmorata are distinct from $L$. multistriata in the dentate lines of forewing, the absence of sexual tufts, and the shape of the female genitalia. However, most species of Lobogonodes and Microlygris sensu Inoue (1992) are indistinguishable in wing pattern and male genitalia. Thus, I synonymize $\mathrm{Mi}$ crolygris with Lobogonodes.

\section{SPECIES InCLuded:}

complicata (Butler, 1879) NEW COMBINATION ssp. dactylotypa Prout, 1940 NEW COMBINATION erectaria (Leech, 1897)

multistriata (Butler, 1889) NEW COMBINATION

$=$ tensa Prout, 1940 NEW SYNONYMY

$=$ athernia Prout, 1937 NEW SYNONYMY

$=$ clasis Prout, 1937 NEW SYNONYMY

permarmorata (Bastelberger, 1909)

porphyriata (Moore, 1888)

taiwana (Wileman and South, 1917)

\section{Eulithis Hübner}

Figures 2I, J, 3A-G, I, 12D, E, 13G, 15C, D

Eulithis Hübner, 1821, Index Exot. Lepid.: [3]. Type species: Petrophora diversilineata Hübner, 1813, Samml. Exot. Schmett. 1: pl. [206], fig. 14, by monotypy.

Euphia Hübner, 1816, Verz. Bekannter Schmett.: 336. Type species: Petrophora diversilineata Hübner, 1813, by subsequent designation (Fletcher, 1966, Entomol. Gaz. 17: 15). Synonymized by Fletcher, 1966: 15.

Lygris Hübner, 1825, Verz. Bekannter Schmett.: 335. Type species: Phalaena populata Linnaeus, 1758, Syst. Nat. (ed. 10) 1: 525, by subsequent designation (Prout, 1905, Trans. London Entomol. Nat. Hist. Soc. 1904: 53). Synonymized by Herbulot, 1964: 376.

Steganolophia Stephens, 1829, Nom. Br. Insects: 44. Type species: Phalaena prunata Linnaeus, 1758, Syst. Nat. (ed. 10) 1: 526, by monotypy [a junior objective synonym of Eulithis, see Ferguson, 1983]

Neolexia Hulst, 1896, Trans. Am. Entomol. Soc. 23: 256, 278. Type species: Neolexia xylina Hulst, 1896, Trans. Am. Eentotmol. Soc. 23: 278 , by original designation. Synonymized by Ferguson, 1983: 101.

Phylace Hulst, 1896, Trans. Am. Entomol. Soc. 23: 256, 277. Type species: Phylace luteolata Hulst, 1896, Trans. Am. Entomol. Soc. 23: 277, by original designation. Synonymized by Ferguson, 1983: 101.

Diagnosis: Species of Eulithis have yellow, white, or brown wings with a contrasting central fascia (figs. 1-3). The central fas- 
ciae of the forewing are band-shaped, or indistinct comprising many oblique lines (e.g., $E$. convergenata). Male sexual tufts are present on the underside of forewing, originating from the basal part of the anal vein. The male genitalia (figs. 12D, E, 13G) are distinguished by the well-developed anellus lobe with long and dense apical hairs, scobinate diaphragma, slender valva with a saccular process, and the presence of cornuti patches on the vesica.

BIOLOGY: Host plants of several Palearctic Eulithis are known: E. prunata and E. mellinata on Ribes (Saxifragaceae); E. testata on Betula (Betulaceae), Populus and Salix (Salicaceae); and E. populata on Vaccinium (Ericaceae)(Skinner, 1984). In North America, $E$. diversilineata and E. gracilineata feed on Vitis and Parthenocissus (Vitaceae); E. propulsata on Ribes (Saxifragaceae); E. destinata and E. flavibrunneata on Salix; and E. xylina on Alnus (Betulaceae), Salix, Rosa, Amelanchier and Potentilla (Rosaceae), Symphoricarpos (Caprifoliaceae), Ribes (McGuffin, 1958). In Japan, E. convergenata feeds on Acer (Aceraceae), Alnus, and Carpinus (Betulaceae); and E. ledereri on Vitis, Parthenocissus, and Schizophragma (Saxifragaceae) (Sato and Nakajima, 1987).

DisTRIBUTION: The genus is Holarctic. Two species, E. testata and E. populata, occur widely from Europe throughout Asia and to North America. In Palearctic, two species are widespread (E. prunata and E. pyropata); two occur in western ( $E$. mellinata, E. roessleraria); and four in eastern (E. convergenata, E. ledereri, E. albicinctata, E. pulchraria). In North America, about 11 species are known: widespread ( $E$. propulsata); northern (E. destinata, E. flavibrunneata); western ( $E$. $x y l i n a, E$. luteolata); eastern ( $E$. diversilineata, E. gracilineata, E. molliculata, E. explanata, E. serrataria, E. testata).

Discussion: The Holarctic genus Eulithis is here redefined by three synapomorphies: the scobinate diaphragma, the narrowed basal part of the anellus lobe, and the cornuti grouped in two patches. The monophyly of Eulithis was first defined by Choi (1997) based on nine apomorphic characters, mainly of the male and female genitalia. Differences between the present analysis and the previous one are due to the inclusion of ten ad- ditional species from North America. The character analysis revealed substantial morphological variability within the genus: male antenna (bipectinate in E. luteolata, E. xylina) (fig. 4); the shape of the apical streak on the forewing; the shape of the male eighth sternite; the shape and length of the saccus; the costa of the valva; the wall of the ductus bursae; and the signum of the corpus bursae.

\section{SPECIES INCLUDED $(*$ indicates unexamined taxon):}

albicinctata (Püngeler, 1909)

= eminens (Prout, 1937) NEW SYNONYMY

convergenata (Bremer, 1864)

destinata (Moschler, 1860)

= schistacea (Warren, 1901) NEW SYNONYMY

*ssp. harveyata (Taylor, 1906)

*ssp. triangulata (Packard, 1873)

diversilineata (Hübner, 1812)

explanata (Walker, 1862)

flavibrunneata (McDunnough, 1943)

gracilineata (Guenee, 1858)

ledereri (Bremer, 1864)

= inurbana (Prout, 1937) NEW SYNONYMY

luteolata (Hulst, 1896)

mellinata (Fabricius, 1787)

molliculata (Walker, 1862)

peloponnesiaca (Rebel, 1902)

*perspicuata (Püngeler, 1909)

*phylaca (Dyar, 1916)

populata (Linnaeus, 1758)

propulsata (Walker, 1862)

prunata (Linnaeus, 1758)

= arctica (Strand, 1901) NEW SYNONYMY

*ssp. teberdensis (Alberti, 1969)

pulchraria (Leech, 1897)

pyropata (Hübner, 1809)

= sugitanii (Prout, 1937) NEW SYNONYMY

*ssp. elegans (Inoue, 1955)

roessleraria (Staudinger, 1870)

*ssp. pseudoledereri (Schwingenschuss, 1939)

serrataria (Barnes \& McDunnough, 1917)

testata (Linnaeus, 1761)

xylina (Hulst, 1896)

ssp. speciosa (Hulst, 1896)

\section{ACKNOWLEDGMENTS}

I would like to thank Fred Rindge, Jim Miller, Eric Quinter, Michael Engel, John Rawlins, and Andy Brower for reading and commenting on the manuscript. Dennis Finnin (AMNH) provided assistance with photographic reproduction. For the loan or gift 
of adult material I thank Hiroshi Inoue, Kauri Mikkola, Lauri Kaila, and Mark Parsons (BMNH). Rikio Sato was very helpful with host plant information. During the study, I was supported at the AMNH by a Kalbfleisch Postdoctoral Fellowship.

\section{REFERENCES}

Beccaloni, G. W.

1997. Ecology, natural history and behaviour of Ithomiine butterflies and their mimics in Ecuador (Lepidoptera: Nymphalidae: Ithomiinae). Trop. Lepid. 8: 103124.

Bolte, K. B.

1990. Guide to the Geometridae of Canada (Lepidoptera). VI. Subfamily Larentiinae. I. Revision of the genus Eupithecia. Mem. Entomol. Soc. Can. 151: 1253.

Brower, A. V. Z.

1996. Parallel race formation and the evolution of mimicry in Heliconius butterflies: a phylogenetic hypothesis from mitochondrial DNA sequences. Evolution 50: 195-221.

Brown, K. S.

1988. Mimicry, aposematism and crypsis in Neotropical Lepidotpera: the importance of dual signals. Bull. Soc. Zool. France 113: 83-101.

Carter, D. J., and B. Hargreaves

1986. A field guide to caterpillars of butterflies and moths in Britain and Europe. London: Collins, 296 pp. +35 pls.

Choi, S.-W.

1997. A phylogenetic study on genera of Cidariini from the Holarctic and the IndoAustralian areas (Lepidoptera: Geometridae: Larentiinae). Syst. Entomol. 22: 287-312.

Dietze, C.

1871. Ueber einige Beispiele von Nachahmung bei Insecten. Stettiner Entomol. Zeitung 32: 279-284.

Dyar, H. G.

1904. Life histories of North American Geometridae. Psyche 11: 29.

Ferguson, D. C.

1983. Larentiinae. In R. W. Hodges et al. (eds.), Check list of the Lepidoptera of America North of Mexico: 101-107. London: E.W. Classey and The Wedge Entomological Research Foundation.

Fisher, R. A.

1930. The genetical theory of natural selection. Oxford: Oxford Univ. Press.
Fletcher, D. S.

1979. Geometridae. In W. B. Nye (ed.), The generic names of moths of the World. Vol. 3. London: British Museum (Natural History).

Forbes, W. T. M.

1948. Lepidoptera of New York and neighboring states, Part II. Cornell Univ. Agric. Exp. Stn. Mem. 274: 5-263.

Ford, E. B.

1955. Moths. London: Collins, 266 pp.

Goloboff, P. A.

1993. NONA: a tree-searching program. Version 1.5, Ms-Dos program and documentation, distributed by the author.

Grossbeck, J. A.

1907. Notes on certain described species of Geometridae, with descriptions of a few new species. Trans. Am. Entomol. Soc. 33: 335-343.

Hampson, G. F.

1895. The fauna of British India, including Ceylon and Burma. Moths, Vol. 3. London: Taylor and Francis, $546+$ xxviii pp.

Herbulot, C.

1964. Corrections a ma mise a jour de la liste des Geometridae de France. Alexanor 3: 376-377.

Holloway, J. D.

1993. The moths of Borneo, Part 11, Geometridae, Ennominae. Kuala Lumpur: Southdene Sdn. Bhd., 309 pp. + 19 pls.

1997. The moths of Borneo: family Geometridae, subfamilies Sterrhinae and Larentiinae. Malay. Nat. J. 51: 1-242.

Inoue, $\mathrm{H}$.

1944. Notes on some Japanese Geometridae. Trans. Kansai Entomol. Soc. 14: 6071.

1982. Geometridae. In H. Inoue (ed.), Moths of Japan, 1: 462-518. Tokyo: Kodansha.

1992. Geometridae. In J. B. Heppner, and H. Inoue (eds.), Lepidoptera of Taiwan 1(2): 111-129. Gainesville: Assoc. for Tropical Lepidoptera.

Jones, J. R. J. L.

1951. An annotated check list of the Macrolepidoptera of British Columbia. Occas. Pap. Entomol. Soc. British Columbia 1: $1-148$.

Joron, M., and J. L.B. Mallet

1998. Diversity in mimicry: paradox or paradigm? Trends Ecol.Evol. 13: 461-466.

Maddison, W. P., and D. R. Maddison

1992. MacClade: analysis of phylogeny and character evolution, Version 3.04. Sunderland: Sinauer. 
Mallet, J., and M. C. Singer

1987. Individual selection, kin selection, and the shifting balance in the evolution of warning colours: the evidence from butterflies. Biol. J. Linn. Soc. 32: 337350.

McDunnough, J.

1943. Notes and descriptions of North American Geometridae (Lepidoptera). Can. Entomol. 75: 211-218.

McGuffin, W. C.

1958. Larvae of the Nearctic Larentiinae (Lepidoptera: Geometridae). Can. Entomol. Suppl. 8: 1-104.

Mikkola, K.

1992. Evidence for the lock-and-key mechanisms in the internal genitalia of the Apamea moths (Lepidoptera, Noctuidae). Syst. Entomol. 17: 145-153.

Miller, J. S.

1996. Phylogeny of the Neotropical moth tribe Josiini (Notodontidae: Dioptinae): a hidden case of Müllerian mimicry. Zool. J. Linn. Soc. 118: 1-45.

Pierce, F. N.

1914. The genitalia of the Geometridae. Liverpool: Northern Publishing, 88 pp. + 48 pls.

Poole, R. W.

1969. The larvae of some species of the genus Stenoporpia from Arizona (Lepidoptera, Geometridae). Can. Entomol. 101: 738-757.

1970. Convergent evolution in the larvae of two Penstemon-feeding geometrids (Lepidoptera: Geometridae). J. Kansas Entomol. Soc. 43: 292-297.

Prout, L. B.

1914-15. The Palearctic Geometrae. In A. Seitz (ed.), The Macrolepidoptera of the world 4: 152-302. Stuttgart: A. Kernen.

1937-38. The Palearctic Geometridae. In A. Seitz (ed.), The Macrolepidoptera of the world 4 (suppl.): 70-215, 233-253. Stuttgart: A. Kernen.
Sato, R., and H. Nakajima

1975. A list of the food-plants of the Japanese Geometridae, I. Ennominae. Japanese Heterocerists'J. Suppl. 2.

1987. Larentiinae. In S. Sugi (ed.), Larvae of larger moths of Japan: 48-69, 272-274. Tokyo: Kodansha. [in Japanese, English summary]

Scoble, M. J.

1992. The Lepidoptera. Form, function and diversity. New York: Oxford Univ. Press, 404 pp.

Sheppard, P. M., J. R. G. Turner, K. S. Brown, W. W. Benson, and M. C. Singer

1985. Genetics and the evolution of Muellerian mimicry in Heliconius butterflies. Philos. Trans. R. Soc. London Biol. Sci. 308: 433-610.

Skinner, B.

1984. Moths of the British Isles (Macrolepidoptera). Harmondsworth: Viking Books, 267 pp.

Vane-Wright, R. I., D. C. Raheem, A. Cieslak, and A. P. Vogler

1999. Evolution of the mimetic African swallowtail butterfly Papilio dardanus: molecular data confrom relationships with $P$. phorcas and $P$. constantinus. Biol. J. Linn. Soc. 66: 215-229.

Viidalepp, J.

1996. Checklist of the Geometridae (Lepidoptera) of the former U.S.S.R. Stenstrup: Apollo Books, $111 \mathrm{pp}$.

Warren, W.

1905. New American Thyrididae, Uraniidae, and Geometridae. Novit. Zool. 12: 307-379.

Wileman, A. E.

1911. New and unrecorded species of Lepidoptera Heterocera from Japan. Trans. Entomol. Soc. London 1911: 189-407, pls. $30-31$.

Xue, D., and H. Zhu

1999. Fauna Sinica, Insecta Vol.15. Lepidoptera, Geometridae, Larentiinae. Beijing: Science Press, 1090 pp. +25 pls. 


Recent issues of the Novitates may be purchased from the Museum. Lists of back issues of the Novitates and Bulletin published during the last five years are available at World Wide Web site http://nimidi.amnh.org. Or address mail orders to: American Museum of Natural History Library, Central Park West at 79th St., New York, NY 10024. TEL: (212) 769-5545. FAX: (212) 7695009. E-MAIL: scipubs@amnh.org 